\title{
Mechanistic Studies of the Stabilization of Insulin Helical Structure by Coomassie Brilliant Blue
}

Sandip Dolui ${ }^{\$ a}$, Ranit Pariary ${ }^{\$ b}$,Achintya Saha ${ }^{c}$, Bhisma N Ratha ${ }^{\mathrm{b}, \dagger}$, Amaravadhi Harikishore ${ }^{\mathrm{d}}$, Susmita Saha $^{\mathrm{e}}$, Snehasikta Swarnakar ${ }^{\mathrm{e}}$, Anirban Bhunia ${ }^{\mathrm{b} *}$ and Nakul C Maiti ${ }^{\mathrm{a} *}$

${ }^{a}$ Structural Biology and Bioinformatics Division, Indian Institute of Chemical Biology, Council of Scientific and Industrial Research, 4, Raja S.C. Mullick Road, Kolkata 700032,India

${ }^{\mathrm{b}}$ Department of Biophysics, Bose Institute, P-1/12 CIT Scheme VII (M), Kolkata, 700054, India.

${ }^{\mathrm{c} D e p a r t m e n t}$ of Chemical Technology, University of Calcutta, 92 AcharyaPrafulla Chandra Road, Kolkata 700009, India

${ }^{\mathrm{d}}$ School of Biological Sciences, Nanyang Technological University, 60 Nanyang Drive, Singapore 637551.

${ }^{e}$ Infectious Diseases and Immunology Division, Indian Institute of Chemical Biology, Council of Scientific and Industrial Research, 4, Raja S.C. Mullick Road, Kolkata 700032,India

Running title: $C B B G$ stabilizes 'partial unfold state' of HI

${ }^{\$}$ both contributed equally

$\dagger$ Present address: Department of Phytopharmaceuticals, Centurion University of Technology and Management, Alluri Nagar, Parlakhemundi 761211, India.

* Address correspondence to

Nakul C. Maiti, Division of Structural Biology and Bioinformatics, CSIR-Indian Institute of Chemical Biology, 4, Raja S.C. Mullick Road, Kolkata 700032, India.

E-mail:ncmaiti@iicb.res.in

Phone: +91-33-2499-5940

Anirban Bhunia, Department of Biophysics, Bose Institute, P-1/12 CIT Scheme VII (M), Kolkata 700054, India.

E-mail: bhunia@jcbose.ac.in or anirbanbhunia@gmail.com

Phone: +91-33-25693336 
Abbreviations: HI, Human insulin; CBBG, Coomassie Brilliant Blue G-250; CD, Circular Dichroism; NOEs, nuclear Overhauser effect; NOESY, nuclear Overhauser effect spectroscopy; TOCSY, total correlation spectroscopy; trNOESY, transferred NOESY; ThT, thioflavin T; ITC, Isothermal calorimetry; MD, molecular dynamics simulation; CSP chemical shift perturbation; CTD, C-terminal domain; PLP, piecewise linear potential. 


\begin{abstract}
Human insulin (HI) is an essential protein hormone and its biological activity mostly depends on folded and active conformation in the monomeric state. The present investigation established that Coomassie Brilliant Blue G-250 (CBBG), a small multicyclic hydroxyl compound can reversibly bind to the hormonal protein dimer and maintained most of $\alpha$-helical folds crucial for biological function of the enzyme. The solution-state 1D NMR and isothermal calorimetric analysis showed a submicromolar binding affinity of the molecule to HI. 2D NOESY NMR established that the HI dimer undergoes residue level local conformational change upon binding to CBBG. The chemical shift perturbation and the NOE parameters of active protons of amino acid residues throughout the polypeptides further suggested that $\mathrm{CBBG}$ upon binding the protein stabilize $\alpha$-helixes of both the A and B subunits of the hormonal protein. The changes in Gibb's free energy $(\Delta G)$ of the binding was of $\sim-11.1 \mathrm{kcal} / \mathrm{mol}$ and suggested a thermodynamically favourable process. The changes in enthalpy $(\Delta H)$ and entropy term $(T \Delta S)$ were $-57.2 \mathrm{kcal} / \mathrm{mol}$ and $-46.1 \mathrm{kcal} / \mathrm{mol}$, respectively. The negative changes in entropy and the NOE transfer effectiveness of several residues in the presence of CBBG molecules indicated that the binding was an enthalpy driven favourable equilibrium process. The NMR-based atomic resolution data and molecular docking studies confirmed that the CBBG binds to $\mathrm{HI}$ at the dimeric stage and prevents the availability of the crucial residue segments that partake directly in further oligomerization and subsequent fibrillation. Extended computational analysis based on chemical shift perturbation of protons of active residues further established receptor-ligand based pharmacophore model comprised of 5 hydrophobic and a hydrogen bond acceptor features that can anchor the residues at the A and B chains of HI and inhibit the partial unfolding and hydrophobic collapse to nucleate the fibrillation. Taken together, the results demonstrated that CBBG and their close analogues might be useful to develop a formulation that will maintain the active and functional form of the hormonal protein for a significantly longer time.
\end{abstract}




\section{Introduction}

Human insulin (HI) is a 51 residues long protein hormone produced in the pancreas and it plays a significant role in glucose metabolism and helped to maintain the normal glucose level in blood. ${ }^{1-5}$ After its synthesis, HI is stored in the pancreatic $\beta$-cells in a hexameric assembly state. ${ }^{6-8} \mathrm{HI}$, in its monomeric form, was comprised of an A chain (21 amino acids) and a long B chain (30 amino acids) linked together by a pair of inter-chain disulfide bonds (Figure 1A). ${ }^{9-11}$ Structurally, A-chain was composed of two $\alpha$-helices at its $\mathrm{N}$-terminus $\left(\mathrm{A}_{2-8}\right) / \mathrm{C}$-terminus $\left(\mathrm{A}_{13-19}\right)$ which are interconnected by an intra chain disulfide linkage forming a short loop at its N-terminus (Figure 1B). In contrast, the Bchain (in its monomer form) was mainly with $\alpha$-helical central region $\left(\mathrm{B}_{8-19}\right)$ flanked by extended N/C terminal segments (Figure 1B). In contrast to A chain, the terminal sequences of HI B chain are shown to adopt extended helical conformation in the presence of allosteric ligands. ${ }^{12,13}$ Strikingly, presence of cofactors $\left(\mathrm{Zn}^{++}\right)$and their coordination with histidine (His $\left.{ }^{\mathrm{B} 10}\right)$ residues was sufficient to induce structural transition from monomer into hexamer state. ${ }^{14,15}$ As a consequence, the N-terminus $\left(\mathrm{B}_{1-8}\right)$ of B chain was shown to adopt two possible states in response to their allosteric ligand concentrations. Therefore, the N-terminus residues of the B-chain adopted an extended conformation as a tense state $(\mathrm{T})^{12}$ in absence of ligands or low $\mathrm{Cl}^{-}$ions or, a helical relaxed state $(\mathrm{R})$ conformation ${ }^{16}$ in presence of allosteric ligands or high $\mathrm{Cl}^{-}$ions, respectively. This kind of conformational transitions and partial unfolding of the protein was also evidenced in the process of its receptor binding. ${ }^{12,17}$

Once released into blood circulation, HI molecules are exposed to undergo dynamic structural transitions from a hexameric form to biologically active monomer ${ }^{18}$ in response to changes in its concentration, physiological $\mathrm{pH}$ as well as allosteric ligands. One of the key determinants to maintain structural stability and function of the HI molecule is to maintain the integrity of helical folds during structural transitions and unfolding steps of HI B chain. This innate loss of structural stability and compactness of the HI structure was increasingly recognised to be associated with a pathological state referred to as amyloidoma in diabetes patients. ${ }^{15,19}$ In this pathological conditions, HI molecule acquires the propensity to form amyloid like fibril aggregates at the site of HI injection. Furthermore, additional factors such as low $\mathrm{pH} /$ high temperature were also suggested to promote the aggregation and fibril formation ${ }^{9,14,15,20-23}$ and affect the stability of HI molecule and thereby reducing its shelf life. $^{21,24}$ 
In the event of fibril formation, it is reported that the $\alpha$-helical domains of the protein open up its hydrophobic regions and in the subsequent event of their collapse triggers amyloidogenesis and formation of unwanted fibrillar aggregates. ${ }^{25-27}$ This physicochemical process often proceeds with an elongated lag-phase, and the subsequent formation of small oligomeric intermediates followed by a sudden growth of formation of $\beta$-sheet rich fibrillar aggregates. ${ }^{14,15,20-23,28-33}$ Using different human HI mutant forms, Nielsen et al proposed a model for HI fibril formation and suggested that a partially folded intermediate triggers the hydrophobic collapse of two monomeric units. This collapse serves as an important starting point for the fibrillation of the protein both in the acidic and physiological $\mathrm{pH}$ condition. ${ }^{34}$ Using solution-state NMR spectroscopic analysis, Hua et al reported that in the early event of fibrillation, partial unfolding of N-terminal helixes of both the A and B chain occurs and the chains detach at least partially from the core of the protein. ${ }^{27}$ They further suggested that the novel detachment of N-terminal helical segments makes possible aberrant hydrophobic (protein/protein) interactions that create the amyloidogenic nucleus and eventually transformed into $\beta$-sheet rich fibrillar aggregates.

To avoid unwanted loss of the protein due to fibrillation, the pharmaceutical formulation of the protein hormone is often made under hexamer stabilizing conditions at near-neutral $\mathrm{pH}$ adding zinc and phenolic excipients. ${ }^{35-37}$ Analogues of the protein are also made to overcome this effect, however, some of the analogues also showed an increased level fibril formation propensity. ${ }^{21,24,35,38,39}$ In the current investigation, we examined the binding interaction of Coomassie Brilliant Blue G-250 (CBBG) with $\mathrm{HI}$ and, its stabilizing effect on the helical folds present in the two peptide chains (A and B) of the protein. Using low- and high-resolution spectroscopic techniques such as circular dichroism (CD) and NMR spectroscopies, respectively, our investigation showed residue specific interaction of the protein and the molecule; it confirmed that the CBBG binding can arrest the $\alpha$-helical folds of the protein even at an amyloidogenic condition $\left(\mathrm{T}=60^{\circ} \mathrm{C}, 25 \mathrm{mM} \mathrm{HCl}, 100 \mathrm{mM} \mathrm{NaCl}, \mathrm{pH} \sim 1.6\right)$ and strongly inhibit the protein fibrillation. The CD spectral analysis demonstrated retention of the native $\alpha$-helix for a longer period of time in the presence of CBBG. The isothermal calorimetric analysis provided several binding parameters and suggested that the stabilization processes was enthalpy driven. Together, our results highlighted that the molecule can provide strong thermal stability to HI and could restrict its partial unfolding event, even at an elevated temperature. The most intriguing and important observation, however, was that the residues which produced the partial fold to nucleate the fibrillation are indeed trapped by CBBG and provided significant stability to the helical domains of the hormonal 
protein. Further, a moderate binding affinity and high thermal (enthalpy) stability of CBBG/HI interaction strongly suggest that the molecule may be potentially useful in the formulation of $\mathrm{HI}$ and used as drug-adjuvant/excipient. In addition, the synergic investigation by NMR and computational analysis established a pharmacophore-model that may aid in designing other small molecules as the stabilizing agent for this wonderful hormonal protein, insulin. 


\section{Results}

\section{Non-toxic CBBG stabilizes the $\alpha$-helical conformation of $\mathrm{HI}$.}

Human insulin (HI) is a globular protein hormone and it contains three helical folds distributed in the A and B polypeptide chains of the protein (Figure 1B). In a harsh condition $\left(\mathrm{T}=60^{\circ} \mathrm{C}, 25 \mathrm{mM} \mathrm{HCl}\right.$, $100 \mathrm{mM} \mathrm{NaCl}, \mathrm{pH} \sim 1.6$ ) it produces a 'novel partial fold' in which the N-terminal segments of both the A- and B- chains partially detach from the core and one of the $\alpha$-helices of the A-chain nucleate the fibrillation process. The present investigation revealed how a non-toxic small molecule, CBBG (Figure 1 and Supporting Figure S1) can retard this unfolding and protect the helical folds even in this severe solution condition of high temperature and low $\mathrm{pH}$. To realize the stabilization effect of the molecule on the protein's secondary structure, far UV circular dichroism (CD) spectroscopic measurements were carried out in the presence and absence of CBBG in acidic condition. Several panels in Figure 2 display the far UV CD spectra of HI in different solution conditions. The circular dichroic (CD) spectrum of HI in its initial state (before heating) showed two minima at $\sim 208$ and $~$ $222 \mathrm{~nm}$ (black curves in Figure 2A and 2B, upper panels), suggestive of predominant presence of $\alpha$ helical structure and in consonance with observations made by previous investigators. ${ }^{10,43}$ As the incubation continued at $60^{\circ} \mathrm{C}, \mathrm{pH} \sim 1.6$, the ellipticity at the two minima was attenuated and a single minimum appeared at around $218 \mathrm{~nm}$ (Figures 2A and 2B, upper panels). This suggested that HI converted from mostly $\alpha$-helix to a $\beta$-sheet structure (Figures $2 \mathrm{~A}$ and $2 \mathrm{~B}$, lower panels) and, similar events were reported earlier. ${ }^{10,43}$ This transformation of the protein's secondary structure to a cross $\beta$ sheet conformation is the good signature of fibrillation of HI. When CBBG was added to HI solution in the molar ratio of $1: 1$, it produced a CD spectrum similar to free $\mathrm{HI}$ at $0 \mathrm{~h}$ of incubation ( red curves in the upper panel of Figure 2A). and, thus the major structural component was $\alpha$-helical (lower panel of Figure 2A). Interestingly, $\alpha$-helical CD signature of HI was largely preserved even after heating at $60{ }^{\circ} \mathrm{C}$ for 2 days (Figure $2 \mathrm{~A}$, shows the $36 \mathrm{~h}$ spectrum). The ratio of the ellipticities at $222 \mathrm{~nm}$ and 208 $\mathrm{nm}$ for the incubated protein in the presence of CBBG was similar to HI solution at $0 \mathrm{~h}$ of incubation and, it remained almost unchanged in the long incubation period. The bottom panel in figure $2 \mathrm{~A}$ shows minimal conformational changes occurred in the presence of CBBG. These results suggested that CBBG can stabilize the native-like solution structure of $\mathrm{HI}$ and retarded the $\alpha$-helix to $\beta$-sheet conformation transition. Upper panel in Figure 2B shows the CD spectrum obtained at different time point of incubation of the protein at the same conditions except the protein concentration was kept 
quite high $(320 \mu \mathrm{M})$. The $\mathrm{CD}$ signatures (Figure $2 \mathrm{~B})$ of this sample also indicated the formation of $\beta$ sheet structure and, due to large amount of fibril formation, background scattering contribution made the baseline erroneous. However, the scattering contribution was significantly less to the CD spectra when the same concentration of protein solution was incubated with CBBG (Figure 2C). The bottom panel of figure 2B shows that the conversion of $\mathrm{HI}$ to $\beta$-sheet rich secondary structure was started at an early time and, subsequently it rapidly converted to $\beta$-sheet structure. Figure $2 \mathrm{C}$ shows CD spectra taken at different time interval of $\mathrm{HI}(320 \mu \mathrm{M})$ incubated with much lower concentration $(30 \mu \mathrm{M})$ of CBBG. It shows that the $\alpha$-helical pattern of the protein was preserved for a longer time (lower panel of Figure 2C) compared to protein alone (lower panel in Figure 2B). All these observations indicated a significant stabilization effect powered by CBBG and it can preserve the $\alpha$-helical folds of HI for a long time.

\section{The insulin-CBBG binding interaction is an enthalpy-driven process}

The binding interaction of CBBG with HI was further studied by isothermal titration calorimetry (ITC) experiment. It indeed provides a direct measurement of thermodynamic parameters (enthalpy, entropy, binding constant, and stoichiometry) describing ligand binding to a macromolecule. Figure 3A shows the raw calorimetric data profile of interaction between $\mathrm{CBBG}$ and $\mathrm{HI}$ at $25^{\circ} \mathrm{C}$. The upper panel shows the thermogram and each of the negative peak represents an exothermic process inferring that heat was released upon injection of the HI into CBBG solution as a function of time. The lower panel in the Figure 3A shows the plot of the integrated heat response obtained from the raw data plotted against the total volume of protein solution added to CBBG solution. The exothermicity of the calorimetry peaks as shown in both the panels in Figure 3A suggests a significant interaction between CBBG and HI and thus the binding interactions between CBBG and HI were mainly exothermic in nature. The binding isotherm (solid line in the lower panel in Figure 3A) of the HI-CBBG interaction was generated by fitting the thermal data points and obtained thermodynamic parameters are given in Table 1. CBBG binds to HI with a moderate affinity. The dissociation constant $(\mathrm{Kd})$ was $12.5 \mu \mathrm{M}$ and, Gibb's free energy of binding $(\Delta \mathrm{G})$ was $-11.1 \mathrm{kcal} / \mathrm{mol}$. CBBG formed a 1:2 complex with $\mathrm{HI}$ as judged from the fitting parameter value of ' $\mathrm{n}$ ' (see Materials and Method) and the changes in enthalpy $(\Delta \mathrm{H})$ and entropy contribution $(\mathrm{T} \Delta \mathrm{S})$ were -57.2 and $-46.1 \mathrm{kcal} / \mathrm{mol}$, respectively. Thus, the $\Delta \mathrm{H}$ and $\Delta \mathrm{S}$ both were negative, and the binding was entropically disfavoured and the association of CBBG with HI was driven mainly by enthalpy contributions. The negative value of $\Delta \mathrm{H}$ and $\Delta \mathrm{S}$ further suggested that the 
binding of HI to CBBG may be dominated by hydrogen bonding and van der Waals interaction. NMR and molecular docking analysis as discussed in the subsequent sections, indeed, supported this finding.

We performed a series of 1D NMR experiments for additional support and understanding the stabilizing effect of CBBG on HI. Figure 3B displays the $1 \mathrm{D}{ }^{1} \mathrm{H}$ NMR spectrum of HI $(100 \mu \mathrm{M}$ HI in $25 \mathrm{mM} \mathrm{HCl}$ buffer ( $\mathrm{pH} \sim 1.6$ ) containing $100 \mathrm{mM} \mathrm{NaCl}$ ) in the presence of different concentration $(0$, $10,25,50,75$ and $100 \mu \mathrm{M})$ of CBBG. The protein alone exhibited distinct sharp peaks in the amide, aromatic and aliphatic regions (Figure 3B). However, the addition of CBBG into the solution of $\mathrm{HI}$ resulted in concentration-dependent broadening and, reduction in overall peak signal intensity of many proton resonances (Figures $3 \mathrm{~B}$ and $3 \mathrm{C}$ ). The uniform loss of signal intensities upon increasing concentrations of CBBG suggested upon a fast to intermediate exchange between the free and CBBGbound $\mathrm{HI}$ at the NMR time scale. ${ }^{21,44}$ The intensity decay rate constants $(\mathrm{Kd})$ of amide, aromatic and aliphatic regions (upon CBBG binding) were determined as $7.54 \pm 2.56 \mu \mathrm{M}, 5.26 \pm 1.64 \mu \mathrm{M}$ and 7.50 $\pm 1.56 \mu \mathrm{M}$, respectively (Figure 3C, Table 1). The binding affinity determined from NMR was in close agreement with the ITC determined Kd values $(12.5 \mu \mathrm{M})$ (Table 1). Parallel to this, we also observed the changes in relative NMR signal intensities of the free and bound CBBG peaks upon titration with HI (Supporting Figure S2). Addition of $10 \mu \mathrm{M}$ of HI fibril to CBBG (500 $\mu \mathrm{M}$ ) revealed nearly $16 \%$ and $11 \%$ reduction in the $1 \mathrm{D}$ NMR signal intensities of the aromatic and aliphatic regions of CBBG (Supporting Figures S2B and S2C). With the addition of $25 \mu \mathrm{M}$ HI to CBBG at 1:20 molar ratio we observed almost negligible chemical shift perturbations but broadening in the highlighted region (Supporting Figure S2), indicating a change in the chemical environment of CBBG. We also attempted transferred NOESY (trNOESY) experiments. However, since CBBG is a rigid molecule, we could not get a sufficient number of trNOE peaks (data not shown).

\section{CBBG binding prevents the formation of 'partial unfolded' state required for nucleation of $\mathrm{HI}$ fibrillation.}

The above observations (ITC and 1D NMR results) clearly showed that CBBG can bind to HI with micromolar affinity and stabilized the helical folds (CD analysis) of the protein. We further examined whether the binding added enough structural stability that could hinder the 'partial unfolding' of the compact helical structures, as observed by several other studies. ${ }^{10,27,43}$ Two experimental methods were employed for the same: (i) thioflavin T (ThT) fluorescence assay measurement that can detect fibrillation of the protein and (ii) 2D NMR analysis. ThT is a small dye molecule that becomes highly 
emissive upon binding to the cradle of the cross- $\beta$-sheet present in amyloid fibrils and produce a typical fluorescence emission spectrum with a peak maximum at $\sim 482 \mathrm{~nm}$ in aqueous solution. ${ }^{45}$ However, in the absence of amyloid fibrils, it fluoresces very weakly. The growth curve (kinetics) was made by measuring fluorescence intensity of ThT in the presence of a quantitative amount of HI samples at different time points of incubation.

Figure 4A displays the time evolution of HI fibrillation based on ThT fluorescence values after incubation of $\mathrm{HI}(100 \mu \mathrm{M})$ at $60{ }^{\circ} \mathrm{C}(\mathrm{pH} 1.6,25 \mathrm{mM} \mathrm{HCl}, 100 \mathrm{mM} \mathrm{NaCl}$ buffer $)$ and it exhibited a typical sigmoid curve comprising of an initial lag phase, in which nothing apparently occurred and, very little amount of amyloid fibril was formed. The presence of baseline level fluorescence represents lag phase and the enhancement in ThT fluorescence suggest the initiation of growth phase and the saturation in ThT fluorescence indicate the completion of fibril formation. The lag phase duration and apparent rate constant (Kapp) of fibrillation were derived from Equation 3 (Materials and Methods section). The resulting time duration/lag phase was found to be as $\sim 1.8 \mathrm{~h}$ and suggested that no major increment of compact $\beta$-sheet structure in the incubated samples for this period of time (Figure 4A, Table 2). Subsequently, the growth phase started, and finally, it reached to a saturated phase within 2 $\mathrm{h}$ and the apparent rate constant for HI fibrillation was calculated as $0.83 \mathrm{~h}^{-1}$ (Figure 4A, Table 2). The fibril formation was also confirmed through AFM images (Figure 5). However, prior to formation of matured fibril it produced oligomer morphology (incubation for $60 \mathrm{~min}$, Figure 5A) and subsequently it produced protofibril structure (Figure 5B). Eventually, after $200 \mathrm{~min}$ of incubation, these protofibrils organized to form long, compact, and dense fibrils with $\sim 10-12 \mathrm{~nm}$ diameters (Figure $5 \mathrm{C}$ ). Thus, the aggregation kinetics of $\mathrm{HI}$ followed a typical sigmoidal nature containing a lag phase association with nucleation and suggested the nucleation-elongation mechanism of fibril formation.

However, HI $(100 \mu \mathrm{M})$ solution co-incubated with CBBG $(100 \mu \mathrm{M})$ at 1:1 molar ratio, growth phase would not appear (red curves in Figure 4A) and fibril formation was not detected Figure 4B shows very weak ThT fluorescence intensity of $\mathrm{HI}$ co-incubated with equimolar CBBG concentration. A relatively higher enhancement of ThT fluorescence intensity was observed after $3 \mathrm{~h}$ of incubation for $\mathrm{HI}$ incubated alone. Incubation in the presence of CBBG was continued for $36 \mathrm{~h}$ and no increase in the ThT fluorescence intensity was observed (Figure 4A). Also, under AFM, we could find no detectable oligomers or fibrillar aggregates from $\mathrm{HI}$ incubated in the presence of CBBG (Figure 5D). We further checked the attenuation effect of $\mathrm{CBBG}$ on $\mathrm{HI}$ fibrillation at ambient $\mathrm{pH}$ of $\sim 7.2$. Figure 
S3 shows the ThT fluorescence profile that represent the aggregation kinetics of HI solution incubated at $\mathrm{pH}$ of 7.2. It also showed a sigmoidal curve with three phases: lag phase, a succeeding growth phase followed by a plateau. In the absence of CBBG, the lag phase was found to be 1.6 days and the apparent rate constant of the fibrillation was 0.88 day $^{-1}$ (Table 2). However, the ThT fluorescence enhancement was not very high and the AFM images confirmed that the aggregates formed at this $\mathrm{pH}$ was amorphous in nature (Figure S4). Figure 4C shows the kinetics of HI fibrillation at higher concentration $(320 \mu \mathrm{M})$ (keeping other solution conditions same i.e. temperature $60{ }^{\circ} \mathrm{C}$, buffer $25 \mathrm{mM}$ $\mathrm{HCl}, 100 \mathrm{mM} \mathrm{NaCl}, \mathrm{pH} \sim 1.6)$ in the absence and in the presence of much low concentrations of CBBG $(7.5 \mu \mathrm{M}, 15 \mu \mathrm{M}, 30 \mu \mathrm{M})$.

Table 2 listed the lag phase durations and the rate constants of the fibrillation. The ThT fluorescence intensity plot indicated that both the nucleation phase (lag phase) and the growth phase were affected; however, the concentration of the protein was $\sim 40$ times higher than the CBBG. The presence of excess concentration of protein compared to CBBG could allow the free protein molecules to aggregate in its way along the inhibition effect $\mathrm{CBBG}$ in the nucleation phase. Figure 4D shows that the relative amount of fibril obtained even in the equilibrium state of fibrillation in the presence of different amount of $\mathrm{CBBG}$ at much lower concentration was very low, while the protein concentration was significantly high. It was further noted that the fibril formation was not evidenced in $100 \mu \mathrm{M}$ protein sample incubated under $5 \mu \mathrm{M}$ CBBG solution (data not shown). A similar observation of no fibrillation was also observed for very low concentration $(1 \mu \mathrm{M})$ of $\mathrm{HI}$ incubated with the same concentration of CBBG (data not shown). These observations suggested that CBBG was effectively interfering with the thermal unfolding and fibrillation of HI.

Further, to evaluate the effect of CBBG on understanding the molecular intricacy of the inhibition process, two-dimensional ${ }^{1} \mathrm{H}-{ }^{1} \mathrm{H}$ NOESY experiments were performed with $\mathrm{HI}$ in the absence and in the presence of CBBG molecule. Figure 6 displays the homonuclear 2D-NOESYspectra of $1 \mathrm{mM} \mathrm{HI}$ in $10 \mathrm{mM}$ sodium phosphate buffer containing $10 \mathrm{mM} \mathrm{NaCl}$ at $\mathrm{pH} 2$ before and after incubation at 60 ${ }^{\circ} \mathrm{C}$ for $24 \mathrm{~h}$ both in the presence and absence of equimolar CBBG molecules. Figure 6A shows a large numbeof HI NOE peaks (at room temperature, before heating) originating from the cross-relaxation between two protons within $5 \AA$ of each other. ${ }^{46}$ The recorded spectrum was similar to previously published NOESY data recorded in the similar experimental conditions. ${ }^{47}$ Surprisingly, after $24 \mathrm{~h}$ of incubation of $\mathrm{HI}$ sample at $60{ }^{\circ} \mathrm{C}$, all the NOE cross-peaks were completely broadened (Figure 6C), 
suggesting the formation of a larger assembly, which were beyond the detection in NMR time scale due to slower tumbling and rapid $\mathrm{T}_{2}$ relaxation. ${ }^{21,47-50} \mathrm{HI}$ sample incubated with equimolar concentrations of CBBG at room temperature also showed NOESY spectra with numerous NOE peaks (Figure 6B). However, incubating the solution for $24 \mathrm{~h}$ at high temperature $\left(60{ }^{\circ} \mathrm{C}\right)$ the NOESY spectrum (Figure 6D) was very similar to the spectra (Figure 6B) obtained before heating the solution. Additionally, 1D NMR time kinetics (Supporting Figure S5) showed 91\% and 93\% decay in signal intensity at aromatic and aliphatic regions for $\mathrm{HI}$ alone after $24 \mathrm{~h}$ incubation, while in the presence of equimolar CBBG the decay of NMR signal intensity were only $14 \%$ and $21 \%$, respectively, suggesting the stabilization of HI in presence of CBBG (Supporting Figure S5C and S5D). Collectively, the data revealed that $\mathrm{CBBG}$ inhibits the formation of NMR-invisible assemblies affecting the overall aggregation kinetics.

\section{Binding epitope of CBBG on insulin that attenuates aggregation}

HI remains quite stable in its zinc-bound hexameric structure. However, in the absence of zinc ion at physiological $\mathrm{pH}(\sim 7.0)$ it is primarily present as a dimer and aggregates very easily at elevated temperatures. At $\mathrm{pH} \sim 2.0$ and room temperature, $\mathrm{HI}$ forms dimmers (due to charge repulsion between $\mathrm{Zn}^{2+}$ and protonated $\left.\mathrm{His}^{\mathrm{B} 10}\right)^{51}$, as confirmed by solution-state $\mathrm{NMR}^{43,47,52}$ and X-ray crystallography. ${ }^{9}$ Dimeric structure of human insulin in sodium phosphate buffer ( $\mathrm{pH} 2.0)$ was indicated by a series of intermolecular NOEs between the two monomers of the dimer (Supporting Figure S6). The intermonomer NOEs of the dimer have been observed for $\mathrm{Gly}^{\mathrm{B} 8} \mathrm{C}_{\alpha} \mathrm{H} / \mathrm{Tyr}{ }^{\mathrm{B} 16} \mathrm{C}_{\varepsilon} \mathrm{H}$, $\quad \mathrm{Ser}^{\mathrm{B} 9} \mathrm{C}_{\alpha} \mathrm{H} / \mathrm{Tyr}^{\mathrm{B} 16} \mathrm{C}_{\varepsilon} \mathrm{H}$, $\mathrm{Ser}^{\mathrm{B} 9} \mathrm{C}_{\beta} \mathrm{H} / \mathrm{Tyr}{ }^{\mathrm{B} 16} \mathrm{C}_{\varepsilon} \mathrm{H}, \quad \mathrm{Ser}^{\mathrm{B} 9} \mathrm{C}_{\alpha} \mathrm{H} / \mathrm{Tyr}{ }^{\mathrm{B} 16} \mathrm{C}_{\delta} \mathrm{H}, \quad \mathrm{Val}^{\mathrm{B} 12} \mathrm{C}_{\gamma} \mathrm{H} / \mathrm{Tyr}^{\mathrm{B} 16} \mathrm{C}_{\varepsilon} \mathrm{H}, \quad \mathrm{Tyr}^{\mathrm{B} 16} \mathrm{C}_{\beta} \mathrm{H} / \mathrm{Tyr}^{\mathrm{B} 26} \mathrm{C}_{\delta} \mathrm{H}$, Gly ${ }^{\mathrm{B} 23} \mathrm{C}_{\alpha} \mathrm{H} / \mathrm{Tyr}{ }^{\mathrm{B} 26} \mathrm{C}_{\delta} \mathrm{H}$, and $\mathrm{Pro}^{\mathrm{B} 28} \mathrm{C}_{\gamma} \mathrm{H} / \mathrm{Tyr}^{\mathrm{B} 16} \mathrm{C}_{\varepsilon} \mathrm{H}$ (Supporting Figure S6). These NOEs corroborated well with the previous study. ${ }^{47,52}$ Apart from these, no other intermolecular NOEs between HI and CBBG were observed.

Figures 7A-B and S7 show the overlap of 2D NOESY NMR spectra for HI and HI/CBBG (1:1) complex at low pH (i.e., $\mathrm{pH}$ 2) before (Figure 7A and S7A) and after heating at $60{ }^{\circ} \mathrm{C}$ for $24 \mathrm{~h}$ (Figure $7 \mathrm{~B}$ and $\mathrm{S7B}$ ). Close inspection suggests that $\mathrm{CBBG}$ interaction causes several chemical shift perturbations (CSPs) as well as line broadening effects for the HI NMR peaks. A detailed analysis of the room temperature 2D NOESY spectra reveals that the several residues from both the HI chains (A and $\mathrm{B}$ ) interact strongly with $\mathrm{CBBG}$. Among the most perturbed residues in the A chain were $\mathrm{Val}^{\mathrm{A} 3}$, $\mathrm{Glu}^{\mathrm{A} 4}, \mathrm{Cys}^{\mathrm{A} 7}, \mathrm{Thr}^{\mathrm{A} 8}$ from the N-terminal $\alpha$-helix and Leu ${ }^{\mathrm{A} 16}$ from $\mathrm{C}$ - terminal helix (Figures $7 \mathrm{C}$ and 
7E). Similarly, $\mathrm{Val}^{\mathrm{B} 2}, \mathrm{Asn}^{\mathrm{B} 3}, \mathrm{Ser}^{\mathrm{B} 9}$ from the $\mathrm{N}$ - terminal region of $\mathrm{B}$ chain $\beta$-turn, $\mathrm{Arg}^{\mathrm{B} 22}$ from the second $\beta$-turn region and $\mathrm{Phe}^{\mathrm{B} 24}$, $\mathrm{Phe}^{\mathrm{B} 25}$ from C-terminal $\beta$-strand, confirmed by chemical shift changes in 2D NOESY spectra (Figures 7C and 7E). This indicates that HI undergoes a local (residue level) conformational change upon binding to $\mathrm{CBBG}$.

Further, before longer incubation time with equimolar concentrations of CBBG (1:1 molar ratio) showed a line-broadening effect for $\mathrm{Glu}^{\mathrm{A} 4}, \mathrm{Gln}^{\mathrm{A} 5}, \mathrm{Cys}^{\mathrm{A} 7}$ and $\mathrm{Tyr}^{\mathrm{A} 19}$ of the A-chain and $\mathrm{Gln}^{\mathrm{B} 4}, \mathrm{Gly}^{\mathrm{B} 8}$, $\mathrm{Ser}^{\mathrm{B} 9}, \mathrm{Val}^{\mathrm{B} 12}, \mathrm{Val}^{\mathrm{B} 18}, \mathrm{Cys}^{\mathrm{B} 19}, \mathrm{Glu}^{\mathrm{B} 21}, \mathrm{Tyr}^{\mathrm{B} 26}$ and $\mathrm{Thr}^{\mathrm{B} 30}$ from the $\mathrm{B}$ chain (Figures $7 \mathrm{~A}$ and S7A). A parallel 1D NMR analysis of the spectra showed the percentage of signal intensity broadening (Supporting Figure S5B). Interestingly, the total proton signal intensity of HI was reduced to 0.71 unit (71\%) in presence of equimolar CBBG concentrations (Supporting Figure S5B). The chemical shift perturbation and broadening of HI NMR peaks indicated the significant binding followed by stabilization of HI sample by CBBG.

Furthermore, the residue-specific interactions with HI dimer were also identified at aggregation-prone conditions i.e., by increasing the sample condition to a temperature of $60{ }^{\circ} \mathrm{C}$ (Figures $7 \mathrm{~B}, \mathrm{~S} 5$ and S7B). The proton NMR spectra of HI upon incubation at high temperatures in the presence of CBBG showed more chemical shift perturbations, line broadenings and the appearance of new signals as shown in the highlighted region in Figure S5A. Interestingly, after $24 \mathrm{~h}$ of incubation at $60{ }^{\circ} \mathrm{C}$ the $2 \mathrm{D}-\mathrm{NOESY}$ NMR spectra showed significant chemical shift changes for the $\mathrm{Val}^{\mathrm{A} 3}, \mathrm{Glu}^{\mathrm{A} 4}, \mathrm{Cys}^{\mathrm{A} 7}, \mathrm{Thr}^{\mathrm{A} 8}$, $\mathrm{Ile}^{\mathrm{A} 10}$, $\mathrm{Cys}^{\mathrm{A} 11}, \mathrm{Leu}^{\mathrm{A} 16}$ and $\mathrm{Tyr}^{\mathrm{A} 19}$ residues from the A-chain and $\mathrm{Ser}^{\mathrm{B} 9}, \mathrm{His}^{\mathrm{B} 10}, \mathrm{Glu}^{\mathrm{B} 13}, \mathrm{Tyr}^{\mathrm{B} 16}, \mathrm{Leu}^{\mathrm{B} 17}, \mathrm{Val}^{\mathrm{B} 18}$, $\mathrm{Arg}^{\mathrm{B} 22}, \mathrm{Phe}^{\mathrm{B} 24}$, $\mathrm{Phe}^{\mathrm{B} 25}$ and $\mathrm{Lys}^{\mathrm{B} 29}$ residues from the B-chain of HI. This data, as represented in Figures $7 \mathrm{D}$ and $7 \mathrm{~F}$, suggests that the $\mathrm{HI}$ dimer undergoes a conformational change upon binding to CBBG at $60^{\circ} \mathrm{C}$. Additionally, remarkable line broadening in presence of $\mathrm{CBBG}$ was observed for the $\mathrm{Glu}^{\mathrm{A} 4}$, $\mathrm{Gln}^{\mathrm{A} 5}, \mathrm{Cys}^{\mathrm{A} 7}$, $\mathrm{Leu}^{\mathrm{A} 16}, \mathrm{Glu}^{\mathrm{A} 17}$ and $\mathrm{Tyr}^{\mathrm{A} 19}$ residues from HI A chain as well as $\mathrm{Gln}^{\mathrm{B} 4}$, Gly ${ }^{\mathrm{B} 8}, \mathrm{Ser}^{\mathrm{B} 9}$, $\mathrm{Val}^{\mathrm{B} 12}, \mathrm{Glu}^{\mathrm{B} 13}, \mathrm{Val}^{\mathrm{B} 18}, \mathrm{Cys}^{\mathrm{B} 19}, \mathrm{Glu}^{\mathrm{B} 21}, \mathrm{Arg}^{\mathrm{B} 22}, \mathrm{Phe}^{\mathrm{B} 25}, \mathrm{Tyr}^{\mathrm{B} 26}$, Lys ${ }^{\mathrm{B} 29}$ and $\mathrm{Thr}^{\mathrm{B} 30}$ residues from the Bchain (Supplementary Figures S7B and S8). These NMR data provided atomic resolution information for the specific location on the HI molecule where the interaction with CBBG takes place.

\section{CBBG Docking and pharmacophore mapping}

To gain further insights into the mechanisms of these molecular interactions, we performed molecular docking of CBBG on HI based on the chemical shift perturbation (CSP) data of ambiguous interaction 
sites. Our results suggested that the CBBG was docked onto the cavity lined by the above highlighted residues at the interface of $\mathrm{A}$ and $\mathrm{B}$ chains of $\mathrm{HI}$ in one monomer with a very good PLP fitness of 82.5 (Figure 8A and 8B). Chemically, CBBG bears a N, N-disubstituted tri-anilinyl-methane scaffold and with an IUPAC chemical name as 3-(((4-((4-((4-ethoxyphenyl)amino)phenyl)(4-(ethyl(3sulfobenzyl)amino)-2-methylphenyl)methyl)-3-methylphenyl)(ethyl)amino)methyl)benzene sulfonate] (Figure 1C). Among the three aniline fragments on CBBG, one fragment - N-ethoxy-phen-4-ylaniline, wherein both the aromatic phenyl rings and the N-ethoxy moieties in this fragment were engaged in hydrophobic interaction with $\mathrm{Ile}^{\mathrm{A} 10}$ (5.46 $\AA, 4.63 \AA$, respectively, Supplementary Figure S9) residues of insulin A subunit. Interestingly, the other two fragments N-ethyl-N-(phenyl-3-sulfonic acid)-2-methyl-aniline were involved in strong hydrophobic interactions with $\mathrm{A}$ and $\mathrm{B}$ subunits, respectively (Figure 9). One of the hydroxyl group of sulfonic acid moiety on the N-phenyl group oriented towards insulin A subunit was involved in hydrogen bonding interaction with main-chain carbonyl atoms of N3 (2.30 ̊). While the '-CH' atoms on N-methyl-phenyl moieties were mediating close $\mathrm{C}-\mathrm{H}$ contacts with carbonyl atoms of main chain $\mathrm{Cys}^{\mathrm{A} 6}(2.64 \AA)$ and strong alkyl and aromatic hydrophobic interactions with $\mathrm{Cys}^{\mathrm{A} 7}$ (3.86 $\AA, 4.95$, respectively). Further, 2-methyl-group on aniline fragment was involved in strong alkyl hydrophobic interaction with $\mathrm{Cys}^{\mathrm{A} 6}$ (4.49 $\AA$ ), $\mathrm{Cys}^{\mathrm{A} 11}$ (4.46 $\AA$ ), $\mathrm{Leu}^{\mathrm{A} 16}$ residues. The aromatic ring of aniline on this fragment was mediating alkyl hydrophobic interaction with Leu ${ }^{\mathrm{B} 11}$ (4.87 A, Supplementary Figure S9).

Similar deep network of both aromatic and alkyl- aromatic was seen predominantly with the other Nethyl-N-(phenyl 3-sulfonic acid)-2-methyl-aniline fragment positioned into the B subunit of HI. The terminal N-ethyl, N- N-(phenyl-3-sulfonic acid)-moieties on 2-methyl-aniline were engaged in alkyl hydrophobic interaction with $\mathrm{Leu}^{\mathrm{B} 17}(4.62 \AA)$ and aromatic interaction of (phenyl-3-sulfonic acid)with $\mathrm{His}^{\mathrm{B} 10}(5.06 \AA)$. The sulfonic acid was not positioned favourably to mediate H-bonding interaction, though it was in close vicinity with $\mathrm{Glu}^{\mathrm{B} 13}$ from both B subunits in the dimer (4.89 $\AA, 3.38$ $\AA$ respectively, Figure 9). Lastly, the 2-methyl-aniline ring was involved in alkyl hydrophobic interaction with $\mathrm{Leu}^{\mathrm{A} 13}(5.02 \AA), \mathrm{Leu}^{\mathrm{A} 16}(5.46 \AA)$ and the phenyl ring of aniline with $\mathrm{Ala}^{\mathrm{B} 14}$ (3.50 , Supplementary Figure S9). Taken together, the strong network of hydrophobic interactions, close contacts and hydrogen bonding interaction at the interface of A and B subunits of HI stabilize the ligand binding and enhance the stability from aggregation. 


\section{Pharmacophore Mapping}

Our NMR results and molecular docking interaction studies have enabled us to map the pharmacophore features at the very important residues involved in interaction with CBBG. Thus, six receptor-ligand based pharmacophore features comprising of five hydrophobic features anchoring $\mathrm{Cys}^{\mathrm{A} 7}, \mathrm{Ile}^{\mathrm{A} 10}, \mathrm{Cys}^{\mathrm{A} 11}, \mathrm{Leu}^{\mathrm{A} 16}$ residues and $\mathrm{Cys}^{\mathrm{B} 7}, \mathrm{Leu}^{\mathrm{B} 11}, \mathrm{His}^{\mathrm{B} 10}, \mathrm{Ala}^{\mathrm{B} 14}$ residues and an acceptor feature in the vicinity of $\mathrm{Cys}^{\mathrm{B} 7}$ and $\mathrm{Asn}^{\mathrm{B} 3}$ residues of $\mathrm{HI}$ were mapped (Figure 9). The exclusion volumes encode the broad contour of protein active site shape and help to prevent clashes of ligand atoms with protein atom. In future works, this vital pharmacophore model on HI protein does help us in identifying novel chemical entities that could prevent HI aggregation and stabilize HI shelf life.

\section{Can CBBG interact with monomeric human insulin?}

It is reported that HI exists as a monomer in $20 \%$ acetic acid. ${ }^{21,43,44}$ To identify the binding epitopes of monomeric $\mathrm{HI}$ by $\mathrm{CBBG}(\mathrm{HI}: \mathrm{CBBG}=1: 1)$, we, again, recorded the NMR spectra of $\mathrm{HI}$ in $20 \%$ acetic acid- $\mathrm{d}_{4}(\mathrm{pH}=1.9)$ at room temperature (Supplementary Figures S10 and S11). 1D and 2D NOESY NMR spectra of $\mathrm{HI}$ in the presence of equimolar CBBG revealed almost no significant chemical shift changes and line broadening effect, indicating that addition of CBBG did not induce any structural conformational changes within the residues of HI (Supplementary Figures S10 and S11). A few residues namely $\mathrm{Cys}^{\mathrm{A} 11}$ and $\mathrm{Ser}^{\mathrm{A} 12}$ (C-terminal helix region) from A-chain and $\mathrm{Leu}^{\mathrm{B} 15}$ and $\mathrm{Phe}^{\mathrm{B} 25}$ from B-chain display negligible chemical shift changes $(<0.007 \mathrm{ppm})$ upon equimolar CBBG addition (Supplementary Figure S11). Collectively, these results indicated that CBBG did not prefer to bind significantly to HI monomer. We further aimed to determine the binding epitope of HI at neutral $\mathrm{pH}$. However, weak solubility of HI in phosphate buffer $(\mathrm{pH} \sim 7)$ hindered to perform similar NMR experiments in neutral $\mathrm{pH}$. All the above-mentioned NMR experiments confirmed that the CBBG molecule can interact with dimeric $\mathrm{HI}$ and stabilizes the helical structure of $\mathrm{HI}$ 


\section{Discussion}

Protein amyloidogenesis has been a pathophysiological phenomenon underlying several of the known degenerative disorders, including Alzheimer's disease, Parkinson's disease, Type 2 diabetes, etc. ${ }^{53}$ Despite the advances, the exact mechanism of aggregation invivo, remains far from being elusive, majorly owing to the complexities and heterogenous properties of the different protein systems. Decades of amyloid research have been dedicated to delineating the intermediate oligomeric or protofibrillar stages that form the pathogenic conformers underlying disease etiology. However, these intermediates form a dynamic heterogeneous pool of several transient conformers, significantly different from the well-defined fibrillar forms, and are difficult to characterize or delineate. ${ }^{23,54}$ Without the atomic-level information on the growth of amyloid fibers, it has been challenging to design inhibitors or excipients to block fiber growth. In this context, it is indispensable to discuss the far-reaching possibilities of NMR experiments to enable the indirect probing of the nucleation events in the amyloidogenic pathways. ${ }^{33,55}$

The protein-folding intermediates have been implicated in harbouring the essential chemical cues that provide useful insight into understanding the amyloidogenic propensity. ${ }^{33,55}$ These intermediates are often structurally similar to the low molecular weight early conformers of the protein but form a chemically distinct pool that nucleates the early aggregation events. High-resolution NMR spectroscopy has helped us to unveil the mechanism of $A \beta$ amyloidogenesis in Alzheimer's disease to be actually a multi-step process involving the docking of the free monomeric forms to the nucleating intermediates. $^{55,56}$ Similarly, in Parkinson's disease, atomic-resolution characterization of the $\alpha$ synuclein protein enabled us to probe the "open" conformation of the monomeric form that serves as the intermediate in initiating the amyloidogenic cascade. ${ }^{56}$ Previous studies have also indicated that the amyloid fibril formation for globular proteins, such as HI, occurs via partially unfolded intermediates that gradually associate to form the oligomers, eventually into well-ordered mature fibrils. ${ }^{9,14,23,27,33,47,57,58}$ A partial unfolding of the monomeric globular protein produces a molten globule like structure that is comparable to the amyloidogenic protein intermediates, acting as the nucleating form. ${ }^{29,50,55,59-61}$

In the absence of zinc at physiological $\mathrm{pH}, \mathrm{HI}$ is primarily present as a conformationally stable dimer; however, it can aggregate at elevated temperatures or during prolonged storage. Coarsely identical to the initial monomeric structure of the protein in buffer solution, these monomeric structures produce 
the lesser known nucleus en route to HI fibrillation. ${ }^{9,14,23,27,33,34,47,57}$ The nucleation step has been identified with the $\mathrm{C}$-terminal end of the $\mathrm{B}$ chain helix turning away from the $\mathrm{C}$-terminal end of the $\mathrm{A}$ chain helix. This causes a partial loss of helicity on the C-terminal of the A-chain, accompanied by a compromise of the intra-chain hydrophobic contacts between Leu ${ }^{16 \mathrm{~A}}$ on A chain C-terminal helix and $\mathrm{Leu}^{15 \mathrm{~B}}$ and $\mathrm{Val}^{18 \mathrm{~B}}$ on the B chain helix. The consequences of the loss of these contacts is an opening up of the structure that creates a hydrophobic cavity in the centre of the protein comprised of the $\mathrm{Phe}^{24 \mathrm{~B}}, \mathrm{Phe}^{25 \mathrm{~B}}, \mathrm{Tyr}^{26 \mathrm{~B}}, \mathrm{Val}^{12 \mathrm{~B}}, \mathrm{Val}^{3 \mathrm{~A}}$, and $\mathrm{Tyr}^{19 \mathrm{~A}}$ residues that may serve as a nucleation site for the very early step of fibrillation. ${ }^{57}$ The NMR analysis defined several residues in the $\alpha$-helical folds of the A chain along with other residues from either terminal segments of both the A and B chains that partake in producing the hydrophobic cavity, prompting the oligomerization events. This atomicresolution characterization has been imperative in enabling us to define efficient pharmaceutical excipients to arrest the aggregation-pro conformer.

The present study suggested the role of CBBG, a close analog of brilliant blue FCF, used as an FDA approved food colour, in a stable binding to the epitope of molten globular intermediate formation in HI aggregation. CBBG induced perturbations of the pivotal unfolding events effectively arrest $\mathrm{HI}$ in the low molecular weight conformations. Interestingly, $\mathrm{CBBG}$ addition at $60{ }^{\circ} \mathrm{C}$ also showed close proximity (NOE contacts) to the Glu ${ }^{13 \mathrm{~B}}$ of the HI B chain, which has been suggested to partake in the dimerization of the domain. ${ }^{57}$ Insulin $\mathrm{B}$ chain has been shown to adopt a $\beta$-hairpin topology wherein the $\mathrm{N}$ and $\mathrm{C}$-terminal ends are held together by hydrophobic contacts and form a homodimer being held together by $\mathrm{Glu}^{13 \mathrm{~B}}$. This dimeric $\beta$-hairpin topology allows the B chain to interact with $\mathrm{A}$ chain residues in the native folds of $\mathrm{HI}$. Glu ${ }^{13 \mathrm{~B}}$ residues of $\mathrm{HI}$ come to close contact with $\mathrm{CBBG}$ because of structural rearrangement during high temperature long incubation at $\mathrm{pH} 2$. The close proximity of sulphonic acid group of $\mathrm{CBBG}$ and $\mathrm{Glu}^{13 \mathrm{~B}}$ residues, suggests a strong interaction between them, as evidenced from the perturbed chemical environment of $\mathrm{Glu}^{13 \mathrm{~B}}$ residues in the CSP data and line broadening of Glu ${ }^{13 B}$ residues. This interaction prevents the unwinding of CTD and stabilizes the HI dimer structure. The NMR-based atomic resolution data collected, and molecular docking studies suggested that the CBBG binds to $\mathrm{HI}$ at the dimeric stage and prevents the availability of the crucial residue segments that partake directly in further oligomerization.

Our results showed that CBBG establishes a strong network of hydrophobic interactions, close contacts, and hydrogen bonding interactions between the two HI chains. These interactions were used 
to map the pharmacophore features of this intricate $\mathrm{CBBG}$ interacting interface that enhance the conformational stability of the arrested intermediates. We strongly believe that the proposed six feature receptor-ligand based pharmacophore model would help in identifying novel chemical entities to be incorporated as part of $\mathrm{HI}$ formulations to increase its shelf-life and pharmacological applications. 


\section{Conclusion and Perspectives}

Our studies demonstrate the rationale behind the usage of small molecules such as CBBG in the production, storage, and delivery of pharmaceutical formulations of human insulin in its most active form. The enthalpy driven binding of CBBG to HI with micromolar affinity allows stabilization of its $\alpha$-helical form, preventing further unfolding of the protein that serves as the nucleation step in $\mathrm{HI}$ fibrillation. The residue-specific interactions provide a clear understanding of the stepwise mechanism of interaction. The ability of CBBG in binding to the specific domains of the dimer that prevent the native unfolding of the protein, hints at its immense potential as an excipiant in insulin formulations. NMR results and computational analysis further lead us to propose a ligand based pharmacophore model comprised of 5 hydrophobic and a hydrogen bond acceptor features that can anchor the residues at $\mathrm{A}$ and $\mathrm{B}$ chains of insulin. In future works, this vital pharmacophore model on HI protein does help us in identifying novel chemical entities that could prevent HI aggregation and stabilize insulin's shelf life. Thus, our observations suggest upon a promising use of CBBG in the efficient production, storage and bio-availability of the active form of hormonal protein insulin. 


\section{Materials and Methods}

\section{Materials and sample preparation.}

Human HI (HI, 91077C), Thioflavin T (ThT), Coomassie brilliant blue G-250 (CBBG), NaCl and HCl were purchased from Sigma-Aldrich. Milli-Q water was used in the preparation of a buffer and stock solution of ThT dye. HI solution was prepared in $25 \mathrm{mM} \mathrm{HCl}$ containing $100 \mathrm{mM} \mathrm{NaCl}$ (pH 1.6) to form a stock solution and then centrifuged at $15000 \mathrm{rpm}$ for $10 \mathrm{~min}$ and passed through a $0.22 \mu \mathrm{m}$ pore size filter to remove any insoluble aggregates. The stock concentration of the protein solution was determined through JASCO-600 UV-vis spectrophotometer, using the extinction coefficient value of the protein studied was as follow $6200 \mathrm{M}^{-1} \mathrm{~cm}^{-1}$ at $276 \mathrm{~nm}$. For inducing amyloid fibrillation, freshly prepared HI $(320 \mu \mathrm{M}$ and $100 \mu \mathrm{M})$ solution in absence and presence of CBBG was incubated for several hours at $60{ }^{\circ} \mathrm{C}$ without agitation.

\section{Circular dichroism (CD) measurements}

Far-UV circular dichroism (CD) spectra were recorded at $25^{\circ} \mathrm{C}$ on a Jasco J-815 spectropolarimeter (Easton, MD). For CD analysis, freshly prepared HI (320 $\mu \mathrm{M}$ and $100 \mu \mathrm{M})$ solution in the absence and presence of CBBG was incubated for several hours at $60{ }^{\circ} \mathrm{C}$ without agitation. HI solutions were prepared in $25 \mathrm{mM} \mathrm{HCl}$ containing $100 \mathrm{mM} \mathrm{NaCl}(\mathrm{pH} \sim 1.6)$. The spectra were measured using diluted aliquots (final concentration was $\sim 15 \mu \mathrm{M}$ of HI) at a different time point of incubation. $300 \mu 1$ of the incubated protein solution was taken in $0.1 \mathrm{~cm}$ path length cuvette and scanned between 200-250 nm with a scanning speed $50 \mathrm{~nm} / \mathrm{min}$, resolution of $0.2 \mathrm{~nm}$. For each sample, the representative spectrum was average of at least three individual scans.

\section{Isothermal Titration Calorimetry (ITC)}

ITC measurements were carried out at $25^{\circ} \mathrm{C}$ on a VP-ITC titration microcalorimeter (Micro Cal Inc., Northampton, MA). HI and CBBG samples were thoroughly degassed on a thermovac before the use in titration. For the correction of heat of dilution, the sample cell was loaded with buffer $(\mathrm{pH} \sim 1.6)$. and the reference cell was also filled with the same buffer solution. The solution in the cell was stirred at $90 \mathrm{rpm}$ by the syringe filled with $0.4 \mathrm{mM} \mathrm{HI}$ in identical buffer solution. Injections of $4 \mu \mathrm{l}$ of the buffer in the syringe were started after stability in baseline reached. 28 sequential such injections were made into the ITC cell containing buffer solution. The titration of the CBBG solution $(0.01 \mathrm{mM})$ in the cell was followed by 28 sequential $4 \mu \mathrm{l}$ injections of $0.4 \mathrm{mM} \mathrm{HI}$ into the ITC cell containing $1.8 \mathrm{ml}$ of 
CBBG solution. The protein and CBBG solution were made in identical buffer condition $(25 \mathrm{mM} \mathrm{HCl}$ containing $100 \mathrm{mM} \mathrm{NaCl}(\mathrm{pH} \sim 1.6)$ ). The raw calorimetric data profile (heat released) of interaction between $\mathrm{CBBG}$ and $\mathrm{HI}$ at $25^{\circ} \mathrm{C}$ were collected automatically and subsequently fitted to a one-site binding model by the Microcal LLC Origin 7.0 software. After subtracting the heat of dilution, a nonlinear least-squares algorithm was used to fit an equilibrium binding equation to the data points (heat flow per injection against the concentration ratio of $\mathrm{HI}$ and $\mathrm{CBBG}$ ). This best fit provides the apparent binding stoichiometry $(n)$, the change in enthalpy $(\Delta H)$, and the dissociation constant $(\mathrm{Kd})$. The change in free energy $(\Delta G)$ and change in entropy $(\Delta S)$ for the binding reaction were analysed by the important equations of thermodynamics.

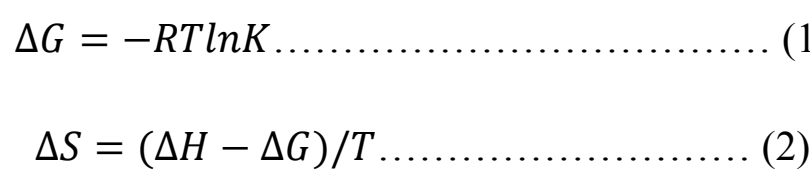

\section{ThioflavinT (ThT) Fluorescence Assay}

ThT fluorescence is recorded to investigate the kinetics associated with fibril formation of human insulin (HI) in different solution conditions. The growth curve (kinetics) was made by measuring fluorescence intensity of ThT in the presence of a quantitative amount of HI samples taken at different time points of incubation of the HI solution in the presence and in the absence of CBBG. Buffer and other sample conditions were similar to samples used in ITC and CD measurements. $4 \mu$ of incubated HI solution (either in the absence or presence with $\mathrm{CBBG}$ ) was pipette out, added to $500 \mu$ l solution of ThT $(\sim 22 \mu \mathrm{M})$ and mixed carefully for the acquisition of fluorescence emission spectra using a Cary Eclipse fluorescence spectrophotometer. The optical path length of the fluorescence cuvette was 10 $\mathrm{cm}$. The fluorescence emission wavelength range was 450-600 nm (excitation $440 \mathrm{~nm}$, emission peak maximum $\sim 482 \mathrm{~nm}$ ). ThT fluorescence peak intensity at $482 \mathrm{~nm}$ was plotted against time, analysed and fitted to the sigmoidal curve using equation $3 .^{14}$

$$
Y=y_{i}+m_{i} x+\frac{y_{f}+m_{f} x}{1+e^{-\left[\frac{\left(x-x_{0}\right)}{\tau}\right]}}
$$

Where $Y$ is the ThT fluorescence intensity at particular time (x), $x$ is the incubation time, and $x_{0}$ is the time to reach $50 \%$ of maximal fluorescence; other parameters are determined by the fitting. The lag 
time is defined by $x_{0}-2 \tau$. Apparent rate constant $(1 / \tau), m_{i}$ and $m_{f}$ are two constants (linear coefficients)

\section{Atomic Force Microscopy}

Morphologies of the insulin aggregates produced in the absence and presence CBBG were performed using Pico plus 5500 ILM AFM system (Agilent Technologies). Incubation and sample conditions were similar to sample prepared for ITC and ThT fluorescence assay measurement described earlier. Micro-fabricated silicon cantilevers (resonance frequency of $300 \mathrm{kHz}$ and spring constant range of 21$98 \mathrm{~N} / \mathrm{m}$ ) was used derive the morphological features of the aggregates formed from the incubated samples. The aliquot taken at defined time of incubation was diluted with water and drop-casting was made on freshly cleaved muscovite mica substrate. The solvent was removed by evaporation at room temperature in the open air. The images were captured with a scan speed of 0.5 lines/sec and processed using Pico view version 1.1 software (Agilent Technologies).

\section{${ }^{1}$ H proton NMR}

All NMR spectra were recorded on Bruker AVANCE III $700 \mathrm{MHz}$, equipped with RT probe and at 298 K. All NMR data acquisition and processing were done by using Topspin v4.0.6 software (Bruker). The interaction of CBBG dye with human HI $(100 \mu \mathrm{M})$ in $25 \mathrm{mM} \mathrm{HCl}$ buffer with $100 \mathrm{mM}$ $\mathrm{NaCl}$ and $10 \% \mathrm{D}_{2} \mathrm{O}$ at $\mathrm{pH} \sim 1.6$ was determined through a series of one-dimensional (1D) ${ }^{1} \mathrm{H}$ proton NMR spectra of $\mathrm{HI}$ in presence of $0,0.1,0.25,0.5,0.75$ and 1 molar excess of CBBG dye (from a stock of $3 \mathrm{mM} \mathrm{CBBG).} \mathrm{The} \mathrm{NMR} \mathrm{signal} \mathrm{intensity} \mathrm{data} \mathrm{were} \mathrm{fitted} \mathrm{by} \mathrm{using} \mathrm{equation} 4$ :

$$
\mathrm{Y}=Y_{O}+\mathrm{A}\left(\frac{\mathrm{X}}{\mathrm{Kd}+\mathrm{X}}\right)
$$

Here, $\mathrm{Y}$ is normalized signal intensity value, $Y_{O}$ is initial signal intensity value, $\mathrm{A}$ is the fraction of fast exchange protons under our condition, $\mathrm{X}$ is the concentration of added CBBG dye $(\mu \mathrm{M})$, and $\mathrm{Kd}$ the apparent intensity decay rate constant or fast exchange rate constant between free and bound CBBG.

Human HI (1 mM) was dissolved in $10 \mathrm{mM}$ sodium phosphate buffer (pH 2.0) containing $10 \mathrm{mM}$ $\mathrm{NaCl}$ and $10 \% \mathrm{D}_{2} \mathrm{O}$, with or without the addition of $\mathrm{CBBG}$ at 1:1 molar ratio for kinetics experiment using NMR. One-dimensional ${ }^{1} \mathrm{H}$ and two-dimensional homonuclear ${ }^{1} \mathrm{H}-{ }^{1} \mathrm{H}$ NOESY NMR spectra (400 ms mixing time) were taken before and/or after incubation of samples at $60{ }^{\circ} \mathrm{C}$ for $24 \mathrm{~h}$. At the 
same time, zinc-free human HI was prepared by the addition of EDTA followed by extensive dialysis and lyophilization. The lyophilized sample was then dissolved in $20 \%$ acetic acid- $\mathrm{d}_{4}$ and $10 \% \mathrm{D}_{2} \mathrm{O}(\mathrm{pH}$ 1.9). NOESY spectra of $350 \mu \mathrm{M}$ HI were performed in the presence or absence of equimolar CBBG dye with a mixing time $200 \mathrm{~ms}$ at $25{ }^{\circ} \mathrm{C} .512$ increments in $\mathrm{t}_{1}$ and 2048 data points in $\mathrm{t}_{2}$ dimension along with excitation sculpting pulse sequence were used for water suppression for all NOESY spectra. The NOESY spectra of HI were also recorded at $25{ }^{\circ} \mathrm{C}$ with 64 scans and a spectral width of $12 \mathrm{ppm}$ for both the dimension. The transferred NOESY (tr-NOESY) experiment (mixing times $=150$ and $250 \mathrm{~ms}$ ) of CBBG was recorded in the presence of $\mathrm{HI}$ fibril at a molar ratio of 1:20 (HI: CBBG, keeping all parameters constant. Parallelly, we also recorded $1 \mathrm{D}{ }^{1} \mathrm{H}$ NMR of $500 \mu \mathrm{M}$ CBBG with the treatment of $10 \mu \mathrm{M}$ and $25 \mu \mathrm{M}$ HI fibrils in $25 \mathrm{mM} \mathrm{HCl}$ containing $100 \mathrm{mM} \mathrm{NaCl}$ and $10 \% \mathrm{D}_{2} \mathrm{O}(\mathrm{pH}$ $\sim 1.6$ ) at $25^{\circ} \mathrm{C}$.

\section{Molecular docking.}

Dimeric assembly of insulin A and B subunits with PDB ID $2 \mathrm{MO}^{40}$ was utilised. The protein assembly was checked for invalid residues / any missing atoms and the overlapping of 25 residues at the interface were corrected using the rotamer library in Discovery studio. The dimer assembly was read with CHARMm force field, heavy atoms constrained, and energy minimized using a cascade of steepest descent 1000 steps and conjugate gradients for 1000 steps in Discovery studio ${ }^{41}$ and thus prepared molecules was used for docking studies.

Using prepare ligand modules, the 2D coordinates of Coomassie blue (CBBG) were converted into 3D and energy minimised using smart minimiser for 2000 steps via minimize ligands tools in Discovery studio. ${ }^{42}$ Gold molecular docking program CSD $2020^{42}$ was utilized to dock the energy minimized ligand CBBG. The NMR CSP data was used to define the active site residues involved in binding of the CBBG and default parameters and GOLD PLP fitness scoring function available with GOLD docking program was used to rank the poses. ${ }^{42}$

\section{Cytotoxicity assay}

Human ovarian cancer SKOV3 cells were obtained from ATCC (ATCC, Manassas, VA, United States). It was maintained in (Roswell Park Memorial Institute) RPMI-1640 medium supplemented with $10 \%$ fetal bovine serum (FBS) and antibiotics $(100 \mu \mathrm{g} / \mathrm{mL}$ penicillin and $100 \mu \mathrm{g} / \mathrm{mL}$ 
streptomycin). It was incubated at $37{ }^{\circ} \mathrm{C}$ in a humidified atmosphere, $5 \% \mathrm{CO}_{2}$. The cells were subcultured every 2-3 days.

The cytotoxicity of the given molecule (CBBG) on SKOV3 cells was determined by MTT (3-(4, 5dimethylthiazol-2-yl)-2, 5-diphenyl tetrazolium bromide). Cells were seeded at a density of $1 \times 10^{4}$ cells per well in 96-well plates Each well contained $100 \mu \mathrm{l}$ of cell suspension, and the plates were incubated for $24 \mathrm{~h}$ at $37{ }^{\circ} \mathrm{C}$ under $5 \% \mathrm{CO}_{2}$ to obtain a monolayer culture. After $24 \mathrm{~h}$ of incubation, the medium was removed from each well. Each well was washed with PBS and then $100 \mu 1$ drug solution solubilised in the incomplete medium in the concentration of $5,10,15,20,30,40 \mu \mathrm{M}$ was added and the experiment was performed in triplicate for each CBBG concentration. The plates were incubated for $24 \mathrm{~h}$ in $5 \% \mathrm{CO}_{2}$ incubation. The supernatant was removed from each well of the plate. Then $100 \mu \mathrm{l}$ of MTT reagent $(5 \mathrm{mg} / \mathrm{ml})$ was added and incubated for $3 \mathrm{~h}$ at $37{ }^{\circ} \mathrm{C}$ in the $\mathrm{CO}_{2}$ incubator. The MTT solution was then discarded and $100 \mu \mathrm{l}$ of DMSO (solubilising reagent) was added. The plates were placed in a dark place for 10 minutes to solubilize the formations of purple crystal formazan. The absorbance was measured using a microplate reader at a wavelength of $570 \mathrm{~nm}$. The results were used to construct a Standard Graph by taking percentage cell viability in Y-axis against a concentration of the drug in $\mathrm{X}$-axis.

Cell viability $(\%)=($ Mean OD/Control OD $) \times 100 \%$ 


\section{Author Contributions}

NCM and AB envisaged the idea, designed the experiments, and analyzed the experimental data, SD and RP performed the experiments; RP analyzed the NMR data with AB; SD, RP, AB, NCM analyzed the results; SD, RP, AB, and NCM wrote the manuscript, BNR helped SD in CD data analysis; SS performing cell cytotoxity experiment in the laboratory of Snehasikta Swarnakar; AH performed molecular modeling studies, AS also helped in initial docking; AS and AH for helpful discussion and reviewing the manuscript.

\section{Acknowledgement}

This work was partly supported by Department of Biotechnology (BT/PR29978/MED/30/2037/2018 to $\mathrm{AB})$ Govt. of India and partly by Bose Institute intramural extramural research fund (R/16/19/1615 to AB). Sandip Dolui thanks CSIR network project BSC0113 for funding support. RP thanks UGC for the research fellowship. The authors thank J. Mandal and T. Murganandan for recording ITC, CD, and AFM measurements. Thanks are also the Directors and associates of the central instrumental facility of CSIR-IICB and Bose Institute for providing all of the instrument facilities. 


\section{References}

(1) Rowlands, A.; Acosta-Gualandri, A.; Guevara-Aguirre, J.; Chanoine, J.-P. WHO and National Lists of Essential Medicines in Mexico, Central and South America, and the Caribbean: Are They Adequate to Promote Paediatric Endocrinology and Diabetes Care? BMJ Glob. Health 2016, 1 (3). https://doi.org/10.1136/bmjgh-2016-000114.

(2) Orci, L.; Ravazzola, M.; Amherdt, M.; Madsen, O.; Vassalli, J. D.; Perrelet, A. Direct Identification of Prohormone Conversion Site in Insulin-Secreting Cells. Cell 1985, 42 (2), 671-681.

(3) Saltiel, A. R.; Kahn, C. R. Insulin Signalling and the Regulation of Glucose and Lipid Metabolism. Nature 2001, 414 (6865), 799-806. https://doi.org/10.1038/414799a.

(4) Cohen, P. The Twentieth Century Struggle to Decipher Insulin Signalling. Nat. Rev. Mol. Cell Biol. 2006, 7 (11), 867-873. https://doi.org/10.1038/nrm2043.

(5) Blundell, T. L.; Cutfield, J. F.; Dodson, G. G.; Dodson, E.; Hodgkin, D. C.; Mercola, D. The Structure and Biology of Insulin. Biochem. J. 1971, 125 (3), 50P-51P.

(6) Bryant, C.; Spencer, D. B.; Miller, A.; Bakaysa, D. L.; McCune, K. S.; Maple, S. R.; Pekar, A. H.; Brems, D. N. Acid Stabilization of Insulin. Biochemistry (Mosc.) 1993, 32. https://doi.org/10.1021/bi00083a004.

(7) Bryant, C.; Strohl, M.; Green, L. K.; Long, H. B.; Alter, L. A.; Pekar, A. H.; Chance, R. E.; Brems, D. N. Detection of an Equilibrium Intermediate in the Folding of a Monomeric Insulin Analog. Biochemistry (Mosc.) 1992, 31, 5692.

(8) Dunn, M. F. Zinc-Ligand Interactions Modulate Assembly and Stability of the Insulin Hexamer-a Review. Biometals 2005, 18. https://doi.org/10.1007/s10534-005-3685-y.

(9) Whittingham, J. L.; Scott, D. J.; Chance, K.; Wilson, A.; Finch, J.; Brange, J.; Guy Dodson, G. Insulin at pH 2: Structural Analysis of the Conditions Promoting Insulin Fibre Formation. J. Mol. Biol. 2002, 318 (2), 479-490. https://doi.org/10.1016/S0022-2836(02)00021-9.

(10) Bouchard, M.; Zurdo, J.; Nettleton, E. J.; Dobson, C. M.; Robinson, C. V. Formation of Insulin Amyloid Fibrils Followed by FTIR Simultaneously with CD and Electron Microscopy. Protein Sci. Publ. Protein Soc. 2000, 9 (10), 1960-1967.

(11) Mayer, J. P.; Zhang, F.; DiMarchi, R. D. Insulin Structure and Function. Biopolymers 2007, 88 (5), 687713. https://doi.org/10.1002/bip.20734.

(12) Menting, J. G.; Yang, Y.; Chan, S. J.; Phillips, N. B.; Smith, B. J.; Whittaker, J.; Wickramasinghe, N. P.; Whittaker, L. J.; Pandyarajan, V.; Wan, Z.; Yadav, S. P.; Carroll, J. M.; Strokes, N.; Roberts, C. T.; IsmailBeigi, F.; Milewski, W.; Steiner, D. F.; Chauhan, V. S.; Ward, C. W.; Weiss, M. A.; Lawrence, M. C. Protective Hinge in Insulin Opens to Enable Its Receptor Engagement. Proc. Natl. Acad. Sci. 2014, 111 (33), E3395-E3404. https://doi.org/10.1073/pnas.1412897111.

(13) Menting, J. G.; Whittaker, J.; Margetts, M. B.; Whittaker, L. J.; Kong, G. K.-W.; Smith, B. J.; Watson, C. J.; Žáková, L.; Kletvíková, E.; Jiráček, J.; Chan, S. J.; Steiner, D. F.; Dodson, G. G.; Brzozowski, A. M.; Weiss, M. A.; Ward, C. W.; Lawrence, M. C. How Insulin Engages Its Primary Binding Site on the Insulin Receptor. Nature 2013, 493 (7431), 241-245. https://doi.org/10.1038/nature11781.

(14) Nielsen, L.; Khurana, R.; Coats, A.; Frokjaer, S.; Brange, J.; Vyas, S.; Uversky, V. N.; Fink, A. L. Effect of Environmental Factors on the Kinetics of Insulin Fibril Formation: Elucidation of the Molecular Mechanism. Biochemistry (Mosc.) 2001, 40 (20), 6036-6046.

(15) Brange, J.; Andersen, L.; Laursen, E. D.; Meyn, G.; Rasmussen, E. Toward Understanding Insulin Fibrillation. J. Pharm. Sci. 1997, 86 (5), 517-525. https://doi.org/10.1021/js960297s.

(16) Kaarsholm, N. C.; Ko, H. C.; Dunn, M. F. Comparison of Solution Structural Flexibility and Zinc Binding Domains for Insulin, Proinsulin, and Miniproinsulin. Biochemistry (Mosc.) 1989, 28, 4427.

(17) Ong, S. C.; Belgi, A.; van Lierop, B.; Delaine, C.; Andrikopoulos, S.; MacRaild, C. A.; Norton, R. S.; Haworth, N. L.; Robinson, A. J.; Forbes, B. E. Probing the Correlation between Insulin Activity and 
Structural Stability through Introduction of the Rigid A6-A11 Bond. J. Biol. Chem. 2018, 293 (30), 11928-11943. https://doi.org/10.1074/jbc.RA118.002486.

(18) Dodson, G.; Steiner, D. The Role of Assembly in Insulin's Biosynthesis. Curr Opin Struct Biol 1998, 8, 189.

(19) Dische, F. E.; Wernstedt, C.; Westermark, G. T.; Westermark, P.; Pepys, M. B.; Rennie, J. A.; Gilbey, S. G.; Watkins, P. J. Insulin as an Amyloid-Fibril Protein at Sites of Repeated Insulin Injections in a Diabetic Patient. Diabetologia 1988, 31, 158.

(20) Waugh, D. F. A Mechanism for the Formation of Fibrils from Protein Molecules. J Cell Physiol Suppl 1957, 49. https://doi.org/10.1002/jcp.1030490415.

(21) Ratha, B. N.; Ghosh, A.; Brender, J. R.; Gayen, N.; Ilyas, H.; Neeraja, C.; Das, K. P.; Mandal, A. K.; Bhunia, A. Inhibition of Insulin Amyloid Fibrillation by a Novel Amphipathic Heptapeptide: Mechanistic Details Studied by Spectroscopy in Combination with Microscopy. J Biol Chem 2016, 291, 23545.

(22) Ivanova, M. I.; Sievers, S. A.; Sawaya, M. R.; Wall, J. S.; Eisenberg, D. Molecular Basis for Insulin Fibril Assembly. Proc. Natl. Acad. Sci. U. S. A. 2009, 106 (45), 18990-18995. https://doi.org/10.1073/pnas.0910080106.

(23) Dolui, S.; Roy, A.; Pal, U.; Saha, A.; Maiti, N. C. Structural Insight of Amyloidogenic Intermediates of Human Insulin. ACS Omega 2018, 3, 2452.

(24) Woods, R. J.; Alarcon, J.; McVey, E.; Pettis, R. J. Intrinsic Fibrillation of Fast-Acting Insulin Analogs. J Diabetes Sci Technol 2012, 6, 265.

(25) Ahmad, A.; Uversky, V. N.; Hong, D.; Fink, A. L. Early Events in the Fibrillation of Monomeric Insulin. J Biol Chem 2005, 280, 42669.

(26) Ahmad, A.; Millett, I. S.; Doniach, S.; Uversky, V. N.; Fink, A. L. Partially Folded Intermediates in Insulin Fibrillation. Biochemistry (Mosc.) 2003, 42, 11404.

(27) Hua, Q. -x.; Weiss, M. A. Mechanism of Insulin Fibrillation the Structure of Insulin under Amyloidogenic Conditions Resembles a Protein-Folding Intermediate. J Biol Chem 2004, 279, 21449.

(28) Sorci, M.; Grassucci, R. A.; Hahn, I.; Frank, J.; Belfort, G. Time-Dependent Insulin Oligomer Reaction Pathway prior to Fibril Formation: Cooling and Seeding. PROTEINS-Struct. Funct. Bioinforma. 2009, 77 (1), 62-73. https://doi.org/10.1002/prot.22417.

(29) Pease, L. F.; Sorci, M.; Guha, S.; Tsai, D.-H.; Zachariah, M. R.; Tarlov, M. J.; Belfort, G. Probing the Nucleus Model for Oligomer Formation during Insulin Amyloid Fibrillogenesis. Biophys J 2010, 99, 3979.

(30) Nettleton, E. J.; Tito, P.; Sunde, M.; Bouchard, M.; Dobson, C. M.; Robinson, C. V. Characterization of the Oligomeric States of Insulin in Self-Assembly and Amyloid Fibril Formation by Mass Spectrometry. Biophys J 2000, 79, 1053.

(31) Kachooei, E.; Moosavi-Movahedi, A. A.; Khodagholi, F.; Ramshini, H.; Shaerzadeh, F.; Sheibani, N. Oligomeric Forms of Insulin Amyloid Aggregation Disrupt Outgrowth and Complexity of Neuron-like PC12 Cells. PLoS One 2012, 7, e41344.

(32) Kurouski, D.; Sorci, M.; Postiglione, T.; Belfort, G.; Lednev, I. K. Detection and Structural Characterization of Insulin Prefibrilar Oligomers Using Surface Enhanced Raman Spectroscopy. Biotechnol. Prog. 2014, 30 (2), 488-495. https://doi.org/10.1002/btpr.1852.

(33) Ratha, B. N.; Kar, R. K.; Bednarikova, Z.; Gazova, Z.; Kotler, S. A.; Raha, S.; De, S.; Maiti, N. C.; Bhunia, A. Molecular Details of a Salt Bridge and Its Role in Insulin Fibrillation by NMR and Raman Spectroscopic Analysis. J. Phys. Chem. B 2020, 124 (7), 1125-1136. https://doi.org/10.1021/acs.jpcb.9b10349.

(34) Nielsen, L.; Frokjaer, S.; Brange, J.; Uversky, V. N.; Fink, A. L. Probing the Mechanism of Insulin Fibril Formation with Insulin Mutants. Biochemistry (Mosc.) 2001, 40 (28), 8397-8409. https://doi.org/10.1021/bi0105983.

(35) Whittingham, J. L.; Edwards, D. J.; Antson, A. A.; Clarkson, J. M.; Dodson, G. G. Interactions of Phenol and $\mathrm{M}$-Cresol in the Insulin Hexamer, and Their Effect on the Association Properties of B28 Pro --> Asp Insulin Analogues. Biochemistry (Mosc.) 1998, 37, 11516. 
(36) Derewenda, U.; Derewenda, Z.; Dodson, E. J.; Dodson, G. G.; Reynolds, C. D.; Smith, G. D.; Sparks, C.; Swenson, D. Phenol Stabilizes More Helix in a New Symmetrical Zinc Insulin Hexamer. Nature 1989, 338 (6216), 594-596. https://doi.org/10.1038/338594a0.

(37) Choudhary, S.; Kishore, N.; Hosur, R. V. Inhibition of Insulin Fibrillation by Osmolytes: Mechanistic Insights. Sci. Rep. 2015, 5 (1), 17599. https://doi.org/10.1038/srep17599.

(38) Hansen, J. F. The Self-Association of Zinc-Free Human Insulin and Insulin Analogue B13-Glutamine. Biophys Chem 1991, 39, 107.

(39) Mathieu, C.; Gillard, P.; Benhalima, K. Insulin Analogues in Type 1 Diabetes Mellitus: Getting Better All the Time. Nat. Rev. Endocrinol. 2017, 13 (7), 385-399. https://doi.org/10.1038/nrendo.2017.39.

(40) Norrman, M.; Schluckebier, G. Crystallographic Characterization of Two Novel Crystal Forms of Human Insulin Induced by Chaotropic Agents and a Shift in pH. BMC Struct. Biol. 2007, 7, 83-83. https://doi.org/10.1186/1472-6807-7-83.

(41) BIOVIA, D.S., Discovery Studio 2020, San Diego: Dassault Systèmes, 2020.

(42) Jones, G.; Willett, P.; Glen, R. C.; Leach, A. R.; Taylor, R. Development and Validation of a Genetic Algorithm for Flexible docking11Edited by F. E. Cohen. J. Mol. Biol. 1997, 267 (3), 727-748. https://doi.org/10.1006/jmbi.1996.0897.

(43) Hua, Q. X.; Weiss, M. A. Comparative 2D NMR Studies of Human Insulin and Des-Pentapeptide Insulin: Sequential Resonance Assignment and Implications for Protein Dynamics and Receptor Recognition. Biochemistry (Mosc.) 1991, 30, 5505.

(44) Pariary, R.; Ghosh, B.; Bednarikova, Z.; Varnava, K. G.; Ratha, B. N.; Raha, S.; Bhattacharyya, D.; Gazova, Z.; Sarojini, V.; Mandal, A. K.; Bhunia, A. Targeted Inhibition of Amyloidogenesis Using a Non-Toxic, Serum Stable Strategically Designed Cyclic Peptide with Therapeutic Implications. Biochim. Biophys. Acta BBA - Proteins Proteomics 2020, 1868 (5), 140378. https://doi.org/10.1016/j.bbapap.2020.140378.

(45) Biancalana, M.; Koide, S. Molecular Mechanism of Thioflavin-T Binding to Amyloid Fibrils. Biochim. Biophys. ACTA-PROTEINS PROTEOMICS 2010, 1804 (7), 1405-1412. https://doi.org/10.1016/j.bbapap.2010.04.001.

(46) Kumar, A.; Ernst, R. R.; Wuthrich, K. A Two-Dimensional Nuclear Overhauser Enhancement (2D NOE) Experiment for the Elucidation of Complete Proton-Proton Cross-Relaxation Networks in Biological Macromolecules. Biochem Biophys Res Commun 1980, 95, 1.

(47) Zheng, Q.; Lazo, N. D. Mechanistic Studies of the Inhibition of Insulin Fibril Formation by Rosmarinic Acid. J. Phys. Chem. B 2018, 122 (8), 2323-2331. https://doi.org/10.1021/acsjpcb.8b00689.

(48) Liu, G.; Prabhakar, A.; Aucoin, D.; Simon, M.; Sparks, S.; Robbins, K. J.; Sheen, A.; Petty, S. A.; Lazo, N. D. Mechanistic Studies of Peptide Self-Assembly: Transient Alpha-Helices to Stable Beta-Sheets. J. Am. Chem. Soc. 2010, 132 (51), 18223-18232. https://doi.org/10.1021/ja1069882.

(49) Sparks, S.; Liu, G.; Robbins, K. J.; Lazo, N. D. Curcumin Modulates the Self-Assembly of the Islet Amyloid Polypeptide by Disassembling Alpha-Helix. Biochem. Biophys. Res. Commun. 2012, 422 (4), 551-555. https://doi.org/10.1016/j.bbrc.2012.05.013.

(50) Fawzi, N. L.; Ying, J.; Torchia, D. A.; Clore, G. M. Kinetics of Amyloid Beta Monomer-to-Oligomer Exchange by NMR Relaxation. J. Am. Chem. Soc. 2010, 132 (29), 9948-9951. https://doi.org/10.1021/ja1048253.

(51) Bryant, C.; Spencer, D. B.; Miller, A.; Bakaysa, D. L.; McCune, K. S.; Maple, S. R.; Pekar, A. H.; Brems, D. N. Acid Stabilization of Insulin. Biochemistry (Mosc.) 1993, 32 (32), 8075-8082. https://doi.org/10.1021/bi00083a004.

(52) JORGENSEN, A.; KRISTENSEN, S.; LED, J.; BALSCHMIDT, P. 3-DIMENSIONAL SOLUTION STRUCTURE OF AN INSULIN DIMER - A STUDY OF THE B9(ASP) MUTANT OF HUMAN INSULIN USING NUCLEARMAGNETIC-RESONANCE, DISTANCE GEOMETRY AND RESTRAINED MOLECULAR-DYNAMICS. J. Mol. Biol. 1992, 227 (4), 1146-1163. https://doi.org/10.1016/0022-2836(92)90527-Q. 
(53) Chiti, F.; Dobson, C. M. Protein Misfolding, Amyloid Formation, and Human Disease: A Summary of Progress Over the Last Decade. Annu. Rev. Biochem. 2017, 86 (1), 27-68. https://doi.org/10.1146/annurev-biochem-061516-045115.

(54) Apetri, M. M.; Maiti, N. C.; Zagorski, M. G.; Carey, P. R.; Anderson, V. E. Secondary Structure of [Alpha]Synuclein Oligomers: Characterization by Raman and Atomic Force Microscopy. J. Mol. Biol. 2006, 355 (1), 63-71. https://doi.org/10.1016/j.jmb.2005.10.071.

(55) Brender, J. R.; Ghosh, A.; Kotler, S. A.; Krishnamoorthy, J.; Bera, S.; Morris, V.; Sil, T. B.; Garai, K.; Reif, B.; Bhunia, A.; Ramamoorthy, A. Probing Transient Non-Native States in Amyloid Beta Fiber Elongation by NMR. Chem Commun 2019, 55 (31), 4483-4486. https://doi.org/10.1039/C9CC01067J.

(56) Bhattacharyya, D.; Kumar, R.; Mehra, S.; Ghosh, A.; Maji, S. K.; Bhunia, A. Multitude NMR Studies of $\alpha-$ Synuclein Familial Mutants: Probing Their Differential Aggregation Propensities. Chem. Commun. 2018, 54 (29), 3605-3608. https://doi.org/10.1039/C7CC09597J.

(57) Ratha, B. N.; Kar, R. K.; Brender, J. R.; Pariary, R.; Sahoo, B.; Kalita, S.; Bhunia, A. High Resolution Structure of A Partially Folded Insulin Aggregation Intermediate. Proteins Struct. Funct. Bioinforma. 2020, n/a (n/a). https://doi.org/10.1002/prot.25983.

(58) Dolui, S.; Mondal, A.; Roy, A.; Pal, U.; Das, S.; Saha, A.; Maiti, N. C. Order, Disorder, and Reorder State of Lysozyme: Aggregation Mechanism by Raman Spectroscopy. J. Phys. Chem. B 2020, 124 (1), 50-60. https://doi.org/10.1021/acs.jpcb.9b09139.

(59) Jain, S.; Udgaonkar, J. B. Evidence for Stepwise Formation of Amyloid Fibrils by the Mouse Prion Protein. J. Mol. Biol. 2008, 382 (5), 1228-1241. https://doi.org/10.1016/j.jmb.2008.07.052.

(60) Kumar, S.; Udgaonkar, J. B. Mechanisms of Amyloid Fibril Formation by Proteins. Curr Sci 2010, $98,639$.

(61) Roy, A.; Chandra, K.; Dolui, S.; Maiti, N. C. Envisaging the Structural Elevation in the Early Event of Oligomerization of Disordered Amyloid $\beta$ Peptide. ACS Omega 2017, 2 (8), 4316-4327.

https://doi.org/10.1021/acsomega.7b00522. 


\section{Figures}
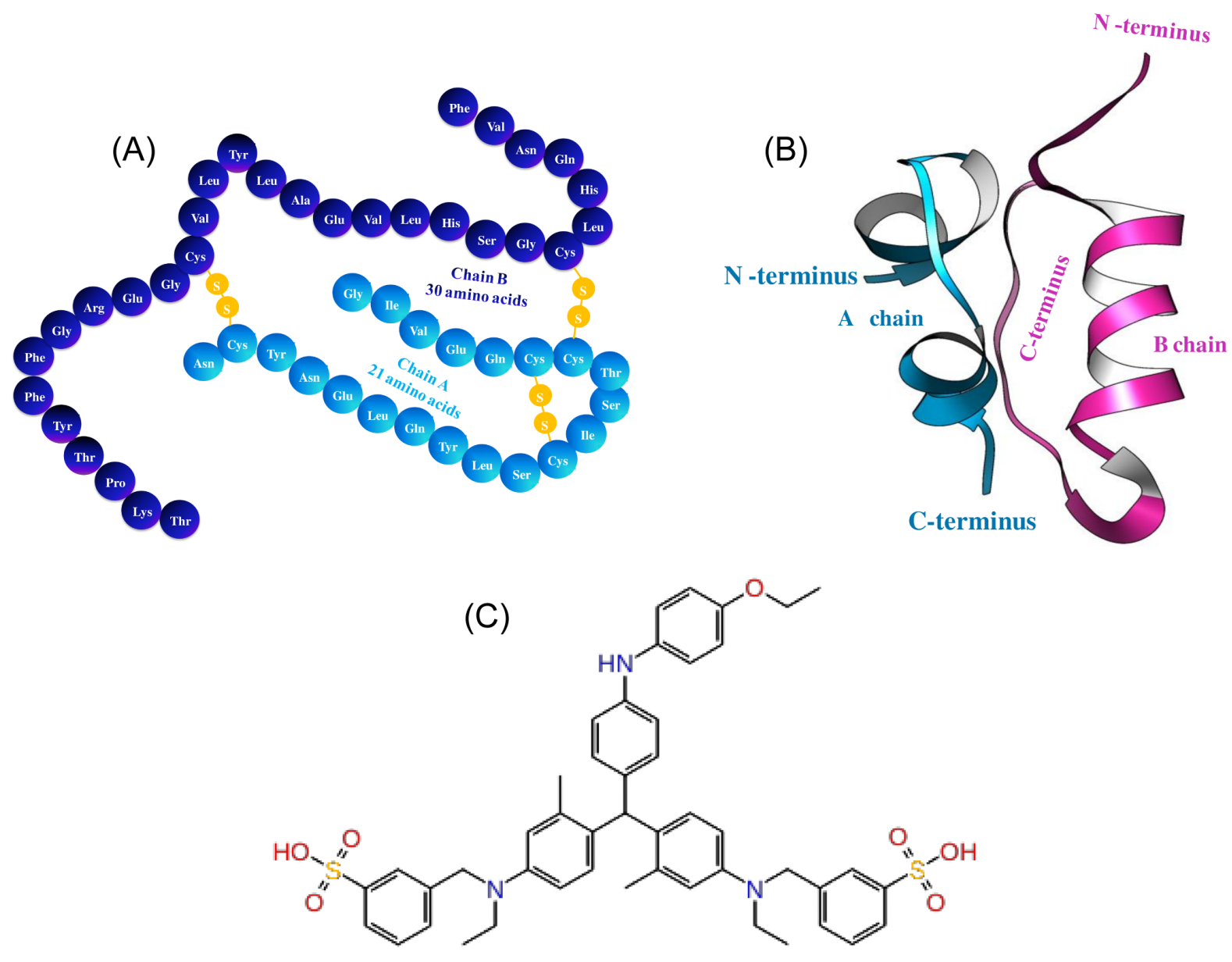

Figure 1. Structure of human insulin (HI) and Coomassie Brilliant Blue G-250 (CBBG). (A) the primary structure of human insulin. The A-chain (skyblue) consists of 21 amino acids and B-chain (deep blue) consist of 30 amino acids they linked by two interchain and one intrachaindisulphidebridge that are highlighted in yellow. (B) The left panel shows a secondary structure of insulin (RCSB Protein Data Bank (PDB) entry 1GUJ; illustrated in Pymol). The A-chain (skyblue) consists of two $\alpha$-helices. The B-chain (pink) features an $\alpha$-helix and a random coil. (C) The lower panel shows the stick model of Coomassie Brilliant Blue G-250 (CBBG). 
(A)
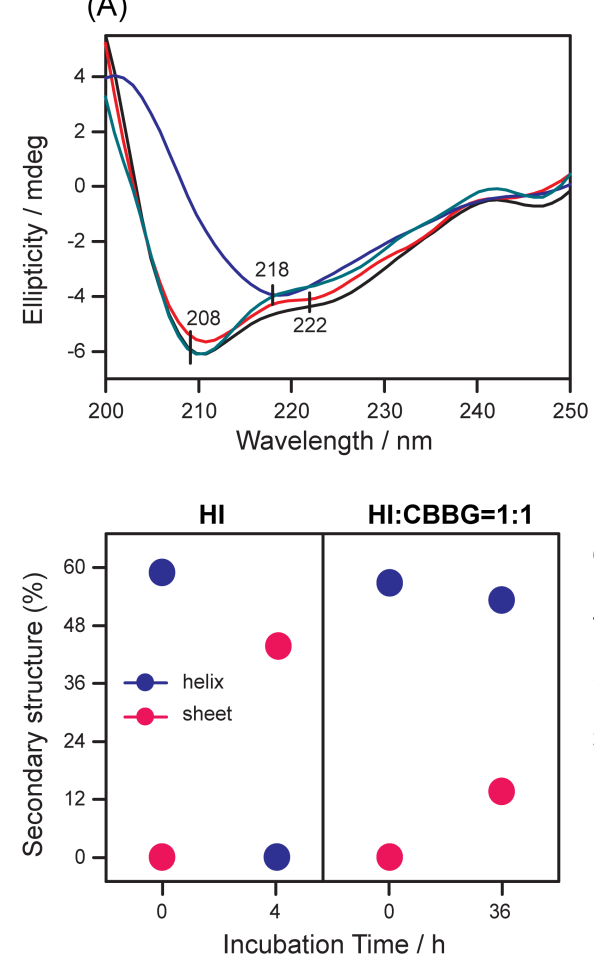

(B)
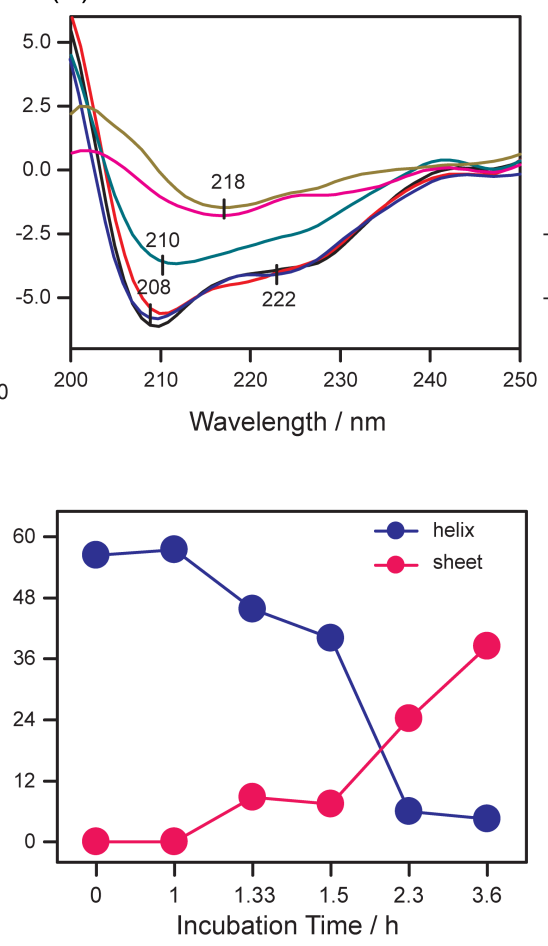

(C)
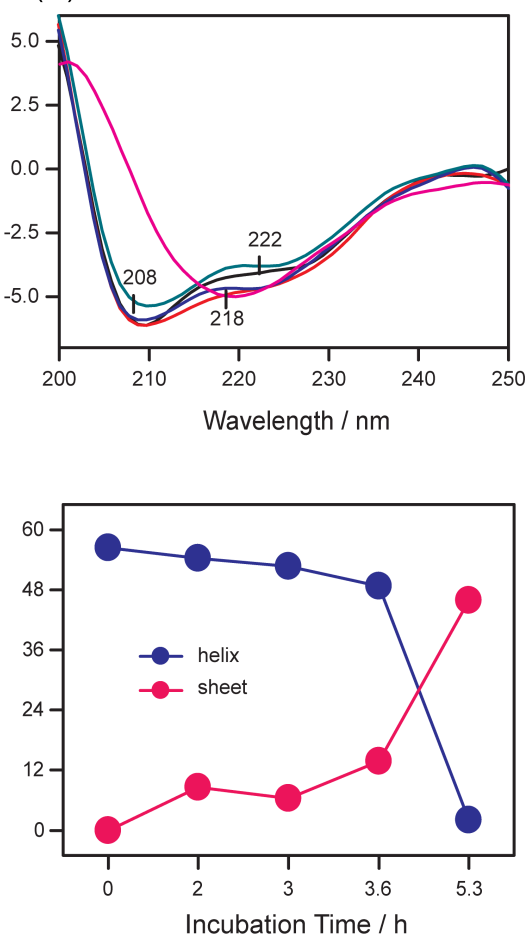

Figure 2. (A) Upper panel shows the CD spectra of $\mathrm{HI}(100 \mu \mathrm{M})$ in the absence and presence of CBBG $(100 \mu \mathrm{M})$ at different time point of incubation $\left(\mathrm{T}=60^{\circ} \mathrm{C}, 25 \mathrm{mM} \mathrm{HCl}, 100 \mathrm{mM} \mathrm{NaCl}, \mathrm{pH}\right.$ 1.6); HI (black trace, $0 \mathrm{~h}$ ), $\mathrm{HI}+\mathrm{CBBG}$ (red trace, $0 \mathrm{~h}$ ), $\mathrm{HI}$ (blue trace, $4 \mathrm{~h}$ ), $\mathrm{HI}+\mathrm{CBBG}$ (green trace, 36 h). Lower panel shows the changes in the secondary structural component (\%) against incubation time: $\alpha$-helix (blue) and $\beta$-sheet (red). (B) CD spectra of insulin solution at different time periods of incubation at high concentration $(320 \mu \mathrm{M})$ : black trace $(0 \mathrm{~h})$, red trace $(1 \mathrm{~h})$, blue trace $(1.33 \mathrm{~h})$, green trace $(1.5 \mathrm{~h})$, pink trace $(2.33 \mathrm{~h})$ and yellow trace $(3.6 \mathrm{~h})$. Lower panel shows the changes in the secondary structural component (\%) against incubation time: helix (blue) and sheet (pink). (C) CD spectra of aggregating insulin $(320 \mu \mathrm{M})$ in the presence of CBBG $(30 \mu \mathrm{M})$ of selected time points: black trace $(0 \mathrm{~h})$, red trace $(2 \mathrm{~h})$, blue trace $(3 \mathrm{~h})$, green trace $(3.6 \mathrm{~h})$ and pink trace $(5.3 \mathrm{~h})$. Lower panel shows the changes in the secondary structural component (\%) against incubation time: helix (blue) and sheet (red). 

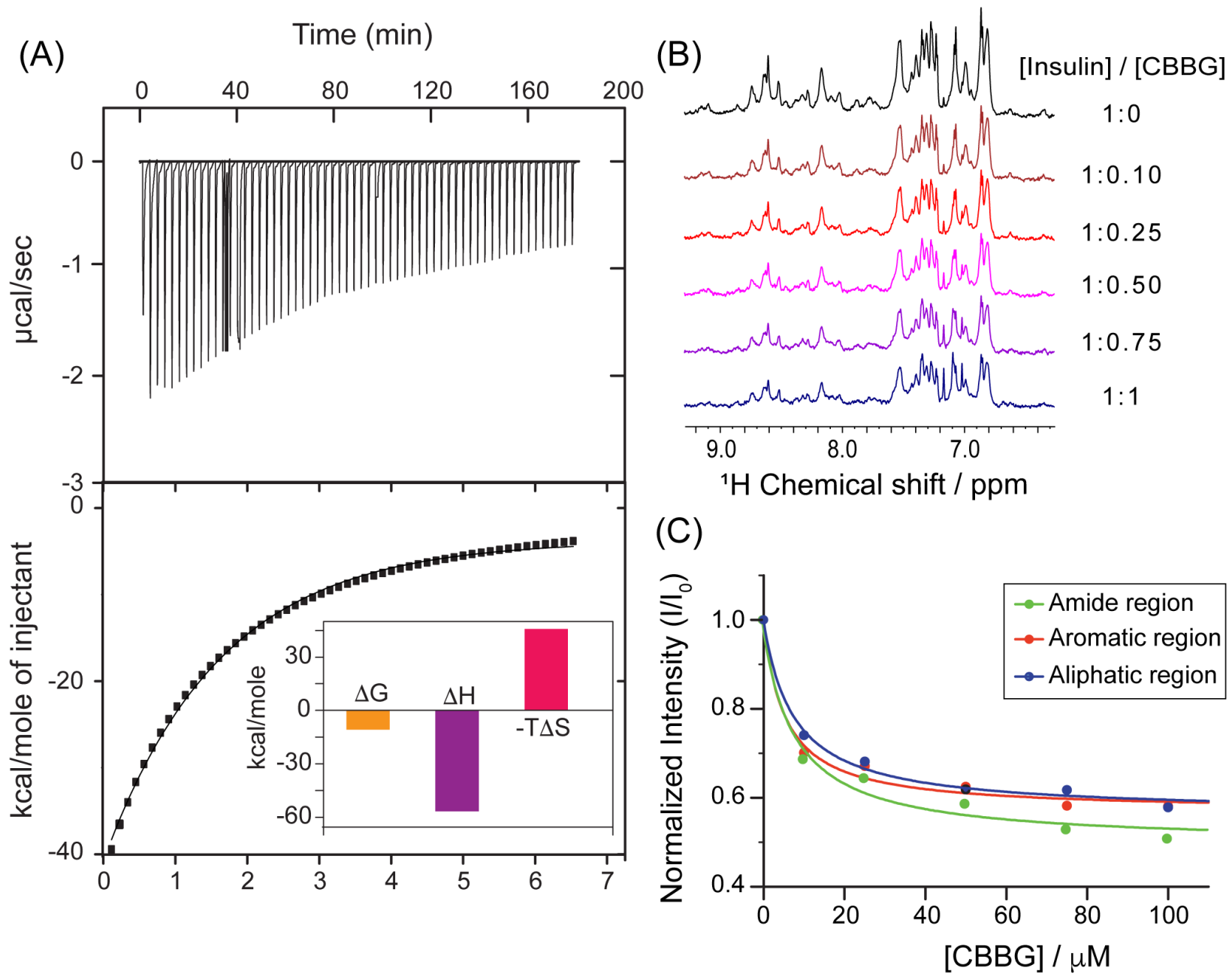

Figure 3. (A) ITC thermogram profile for insulin binding to CBBG. The upper panel presents the raw heat effects against time for the titration of $\mathrm{CBBG}(0.01 \mathrm{mM})$ with insulin $(0.4 \mathrm{mM})$ in aqueous $\mathrm{HCl}$ solution ( $25 \mathrm{mM} \mathrm{HCl}, 100 \mathrm{mM} \mathrm{NaCl}, \mathrm{pH} \sim 1.6)$ at $25^{\circ} \mathrm{C}$. The bottom panel shows the integrated heat data after correction of the heat of dilution against the molar ratio of CBBG to insulin. The black line indicates the fitted curve assuming a one-site binding model with one type of site. The binding free energy $(\Delta G)$, enthalpy $(\Delta H)$, and entropy $(\Delta S)$ of insulin to CBBG is shown in inset. (B) ${ }^{1} \mathrm{H}$ NMR spectra of $100 \mu \mathrm{M}$ insulin in $25 \mathrm{mM} \mathrm{HCl}$ buffer with $100 \mathrm{mM} \mathrm{NaCl}$ ( $\mathrm{pH} \sim 1.6$, black curve) and the presence of a different concentration of $\mathrm{CBBG}$ at $25^{\circ} \mathrm{C}$. The concentration of $\mathrm{CBBG}$ were varied from $10 \mu \mathrm{M}$ to $100 \mu \mathrm{M}$. (C) The NMR proton peak intensity decay of aliphatic (blue) aromatic (red) and amide (green) region of insulin upon titration with $\mathrm{CBBG}$. 

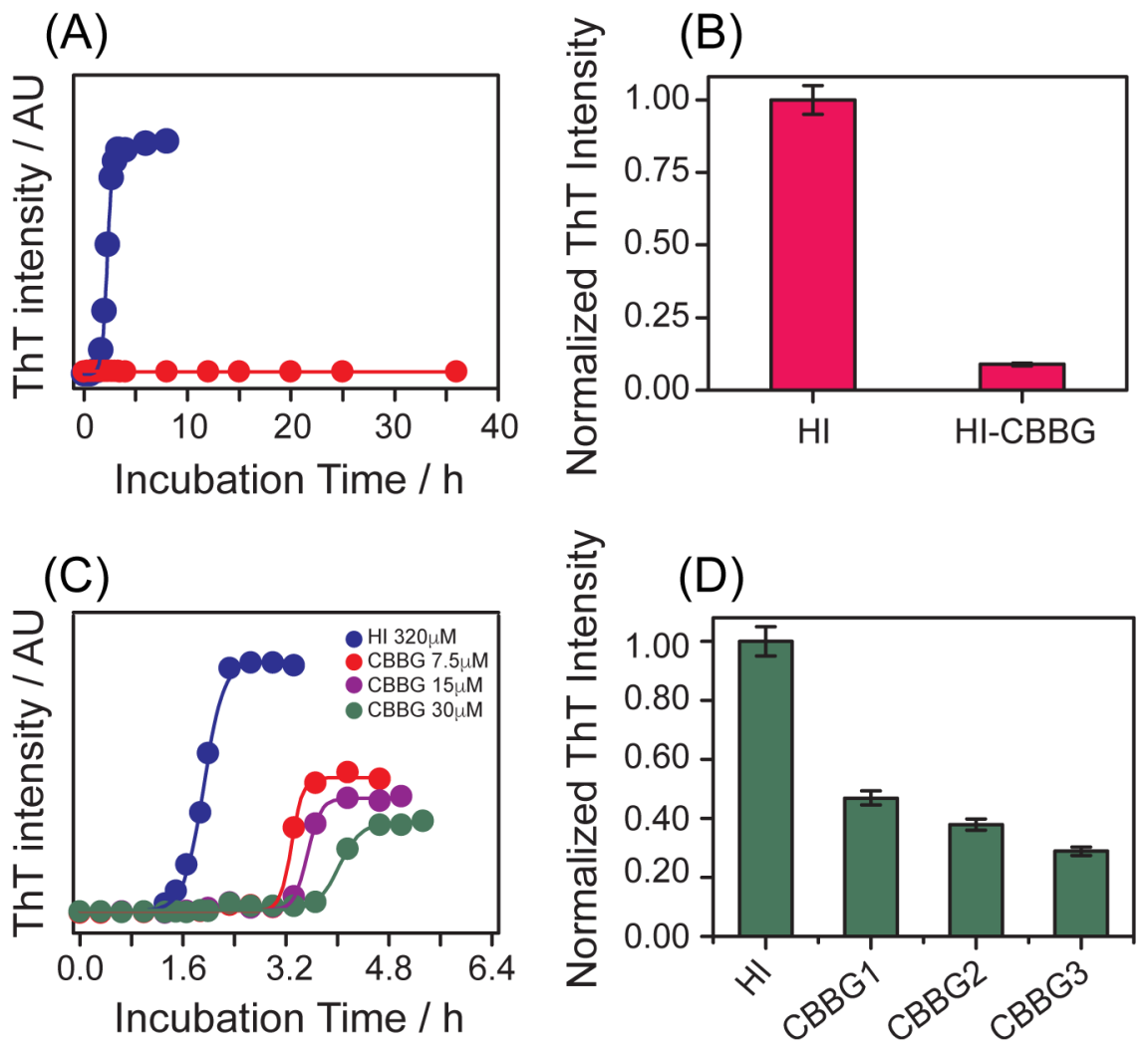

Figure 4. ThT fluorescence assay of insulin (HI) fibrillation in different solution conditions (details are provided in the Materials and Methods section): (A), ThT fluorescence intensity at $482 \mathrm{~nm}$ in the presence of the quantitative amount of incubated HI solution at a different time point of incubation. Incubation condition, $100 \mu \mathrm{M}$ insulin, temperature $60{ }^{\circ} \mathrm{C}, 25 \mathrm{mM} \mathrm{HCl}, 0.1 \mathrm{M} \mathrm{NaCl}, \mathrm{pH} \sim 1.6$, without CBBG (blue trace) and in the presence of $100 \mu \mathrm{M} \mathrm{CBBG} \mathrm{(red} \mathrm{trace);} \mathrm{(B),} \mathrm{normalized} \mathrm{(with} \mathrm{respect} \mathrm{to}$ 0 concentration of $\mathrm{CBBG}$ ) ThT fluorescence intensity (at $482 \mathrm{~nm}$ ) at equilibrium (after five hours of incubation) of insulin incubated in the absence and presence of $\mathrm{CBBG}$, other solution conditions are same as in A; (C), plot of ThT fluorescence intensity against time, similar to (A) for HI incubated at higher concentration $(320 \mu \mathrm{M})$ and, in the absence and presence of a different amount of CBBG (7.5, 15 and $30 \mu \mathrm{M}$ ). (D) Normalized (with respect to 0 concentration of CBBG) ThT fluorescence intensity at equilibrium of the samples described in (C) and marked as $\mathrm{HI}(\mathrm{HI}+0 \mu \mathrm{M}$ of CBBG), $\mathrm{CBBG} 1(\mathrm{HI}+$ $7.5 \mu \mathrm{M}$ CBBG), CBBG2 (HI +15 $\mu \mathrm{M}$ CBBG) and CBBG3 (HI +30 $\mu \mathrm{M}$ CBBG). 

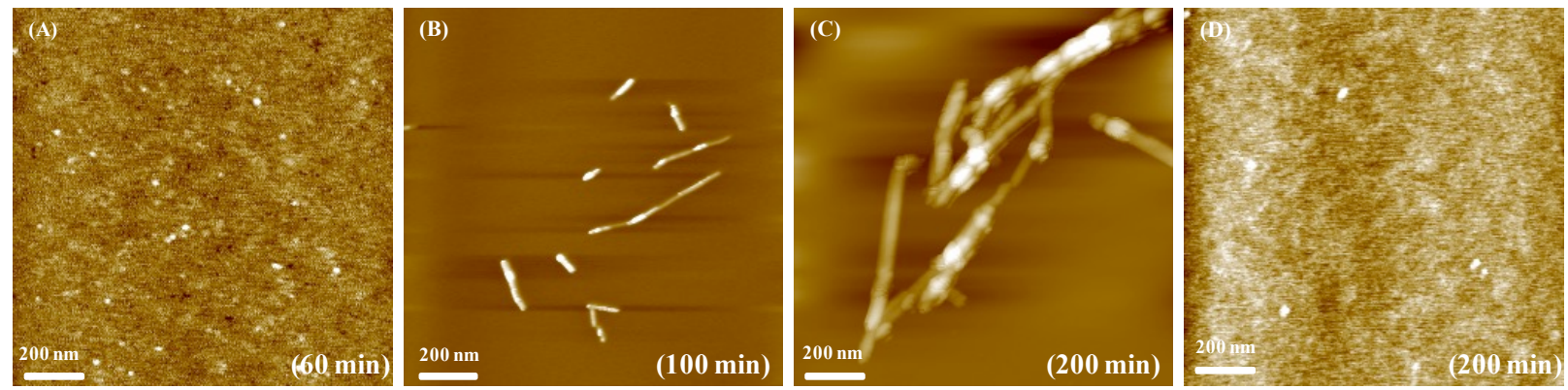

Figure 5. Representative AFM images showing aggregate morphology at several time point of $\mathrm{HI}$ $\left(100 \mu \mathrm{M}\right.$ ) incubation (temperature $\left.60{ }^{\circ} \mathrm{C}, 25 \mathrm{mM} \mathrm{HCl}, 0.1 \mathrm{M} \mathrm{NaCl}, \mathrm{pH} \sim 1.6\right)$ in the absence and the presence of CBBG $(100 \mu \mathrm{M})$. (A), (B) and (C) represent the surface morphology of the aggregates formed at $1 \mathrm{~h}, 1.6 \mathrm{~h}$ and $3.6 \mathrm{~h}$, respectively, of insulin samples incubated without CBBG. (D) Represent the morphology of $\mathrm{HI}$ in the presence of CBBG at $3.6 \mathrm{~h}$ and no effective aggregates could be found. Scale bar is $200 \mathrm{~nm}$. 
(A)
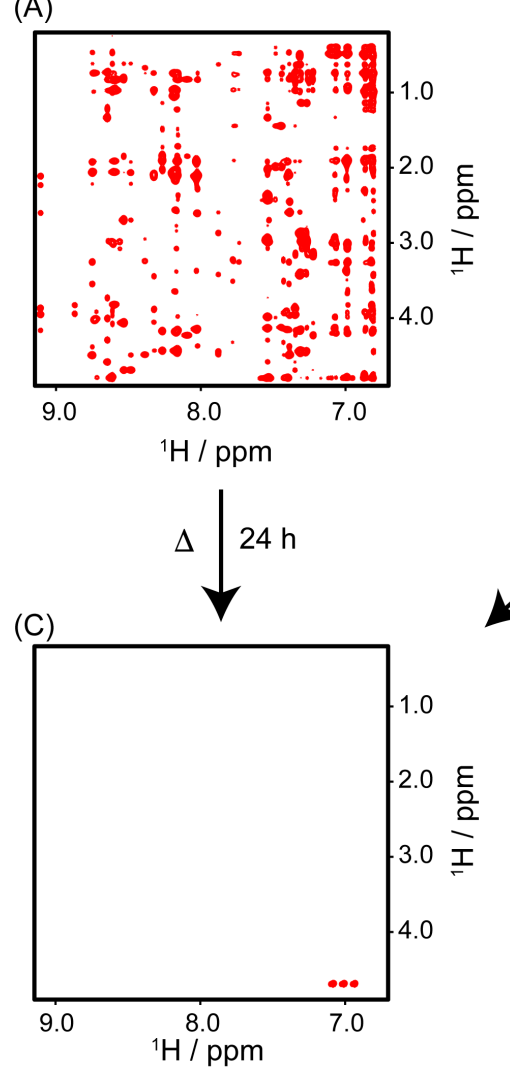

(B)

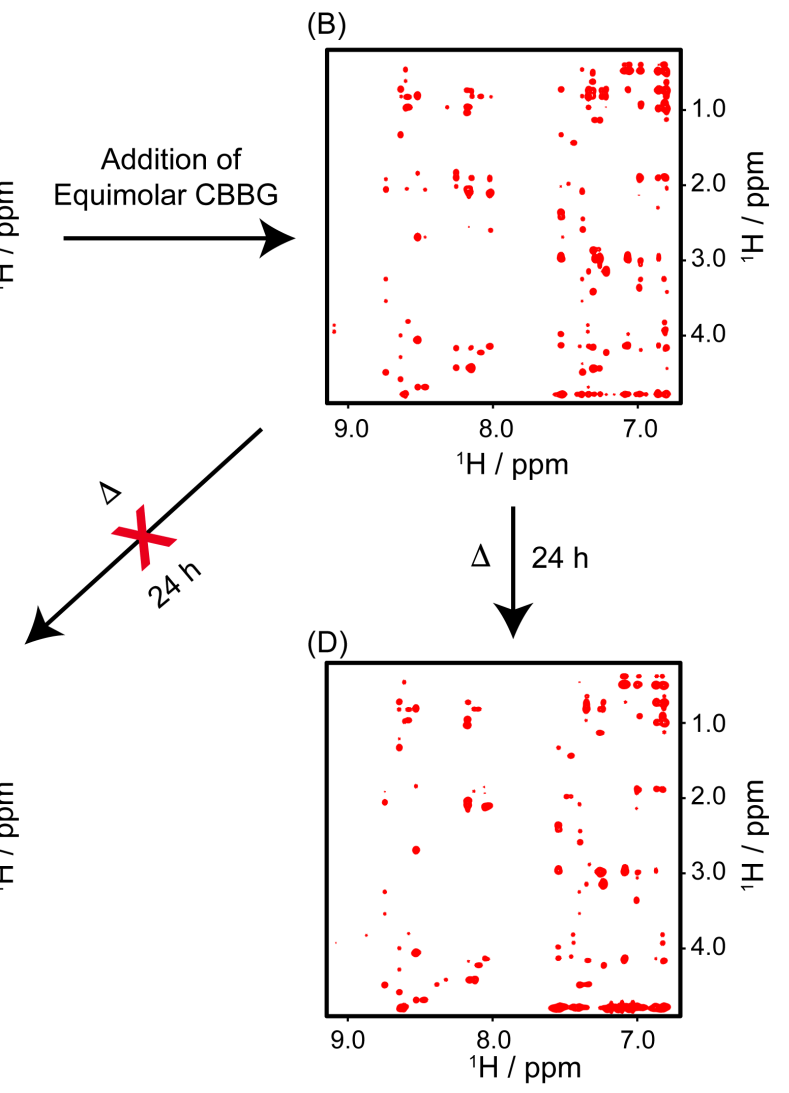

Figure 6. Inhibition of insulin amyloid fibrillation by CBBG. Two-dimensional NOESY NMR spectra: (A), insulin in the absence of $\mathrm{CBBG}$ and (B) in the presence of CBBG (B) just before incubation; (C) insulin solution after heating at $60{ }^{\circ} \mathrm{C}$ for $24 \mathrm{~h}$ shows no cross peak and (D) insulin co-incubated with equimolar $\mathrm{CBBG}$ at $60{ }^{\circ} \mathrm{C}$ for $24 \mathrm{~h}$ shows almost identical cross peak recorded before incubation (B). The experiment was performed in $10 \mathrm{mM}$ sodium phosphate, $10 \mathrm{mM} \mathrm{NaCl}$ $(\mathrm{pH}=2.0)$ and $10 \% \mathrm{D}_{2} \mathrm{O}$ using Bruker Avance III $700 \mathrm{MHz}$ at $25^{\circ} \mathrm{C}$. 

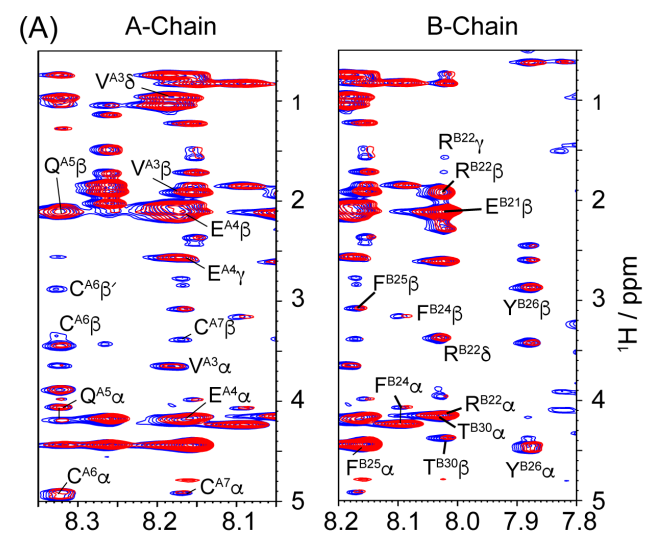

(B)
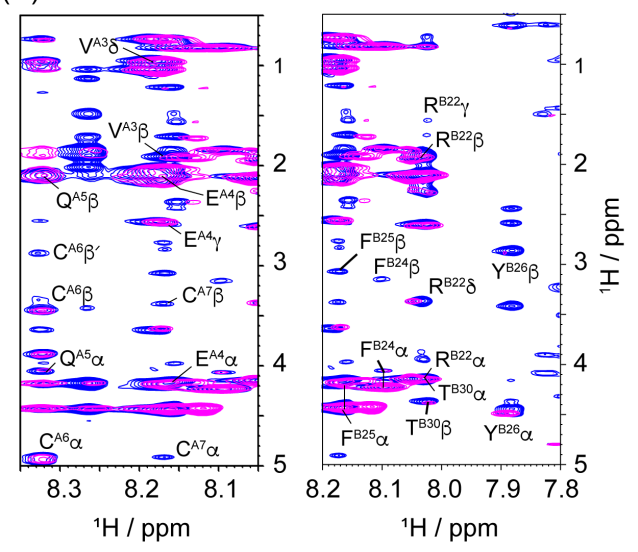

(C)

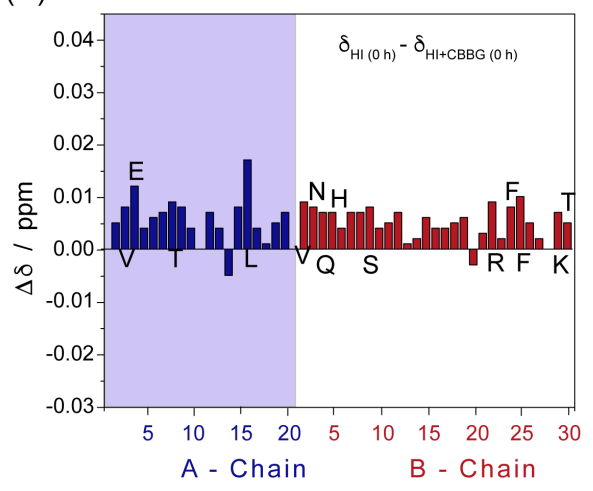

(D)

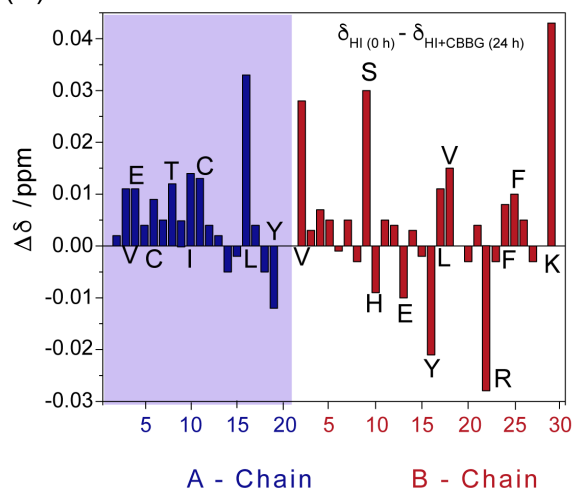

(E)

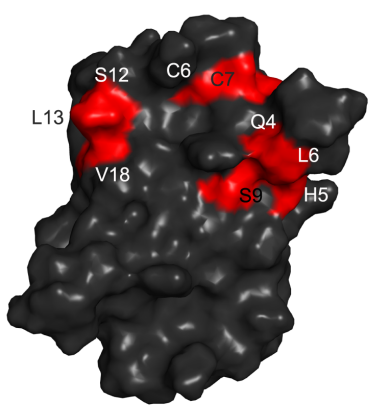

(F)

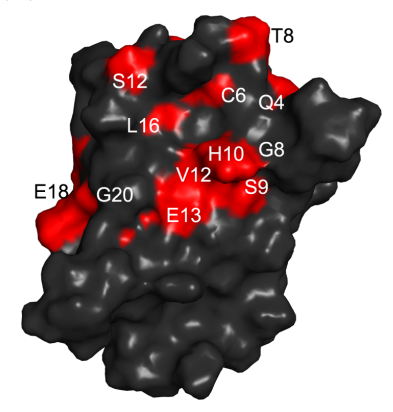

Figure 7. Structural insights into the insulin amyloid inhibitory interaction with CBBG. Twodimensional NOESY NMR fingerprint region of interaction site of CBBG in insulin A and B-chains before (A) and after (B) incubation for $24 \mathrm{~h}$ at $60^{\circ} \mathrm{C}$ in $10 \mathrm{mM}$ sodium phosphate (pH 2.0) containing $10 \mathrm{mM} \mathrm{NaCl}$ and $10 \% \mathrm{D}_{2} \mathrm{O}$. Blue, red and purple colours represent insulin (A and $\mathrm{B}$ ), insulin-treated with equimolar $\mathrm{CBBG}$ (insulin: $\mathrm{CBBG}=1: 1$ ) before heating (A) and after heating (B) at $60{ }^{\circ} \mathrm{C}$, respectively. The changes in proton chemical shift $(\Delta \delta)$ of insulin residues were visible both in Achain and B-chain of insulin, before (C) and after (D) heating of insulin complex (insulin: $\mathrm{CBBG}=$ $1: 1)$ at $60{ }^{\circ} \mathrm{C}$ for $24 \mathrm{~h}$. Chemical shift change $(\Delta \delta)$ of alpha protons $(\alpha-\mathrm{H})$ were calculated from the difference between the chemical shift of respective residues of insulin $\left(\delta_{\mathrm{HI}}\right)$ at $0 \mathrm{~h}$ and insulin $+\mathrm{CBBG}$ $\left(\delta_{\mathrm{HI}+\mathrm{CBBG}}\right)$ at 0 or $24 \mathrm{~h}$, respectively. 2D-NOESY NMR spectra were recorded on Bruker Avance III $700 \mathrm{MHz}$, equipped with RT-probe. (E) and (F) are the mapping of chemical shift perturbed residues onto the surface of insulin dimeric structure at $25^{\circ} \mathrm{C}$ and $60^{\circ} \mathrm{C}$, respectively; clearly delineates and points to the binding cavity at the interface of A- and B-chains of insulin (at which CBBG could be docked). 

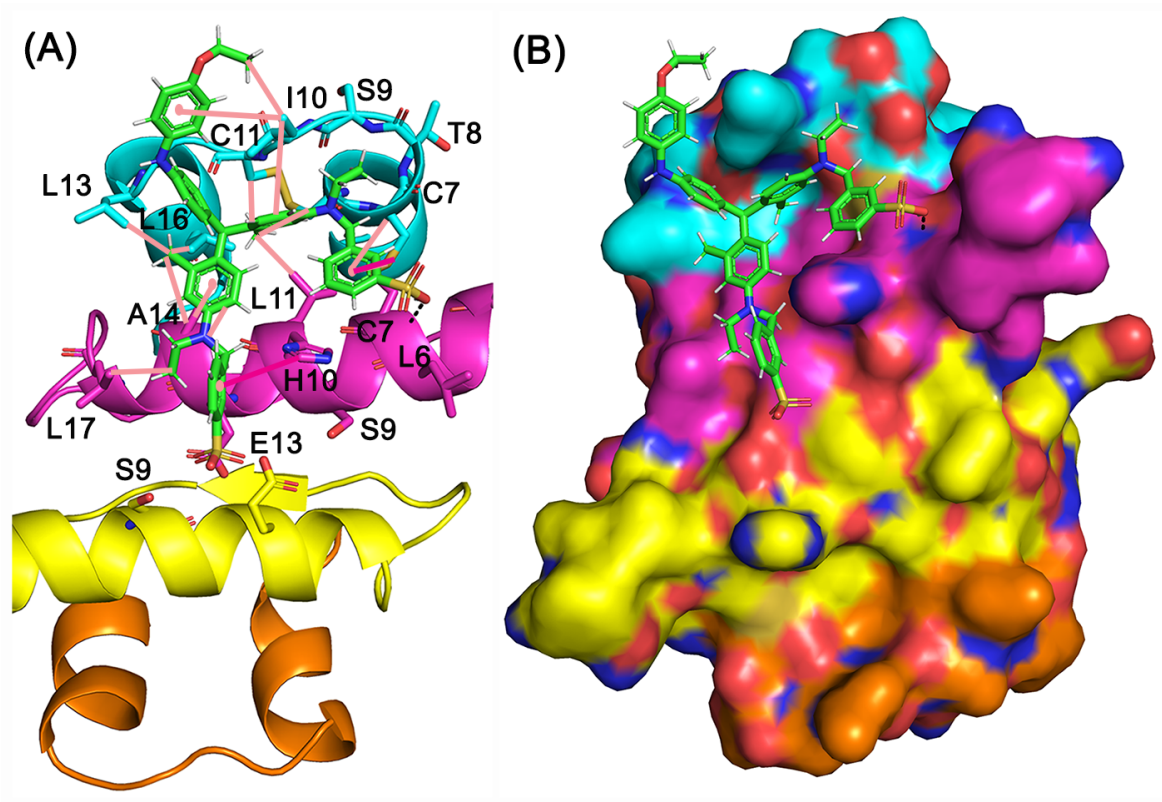

Figure 8. Binding model of CBBG at the dimeric interface of insulin A, B subunits. (A) Cartoon model of CBBG binding highlighting the predominant network of alkyl hydrophobic interactions (pink lines) and aromatic interactions (magenta). (B) Surface view of CBBG best pose at the dimer interface.

(A)

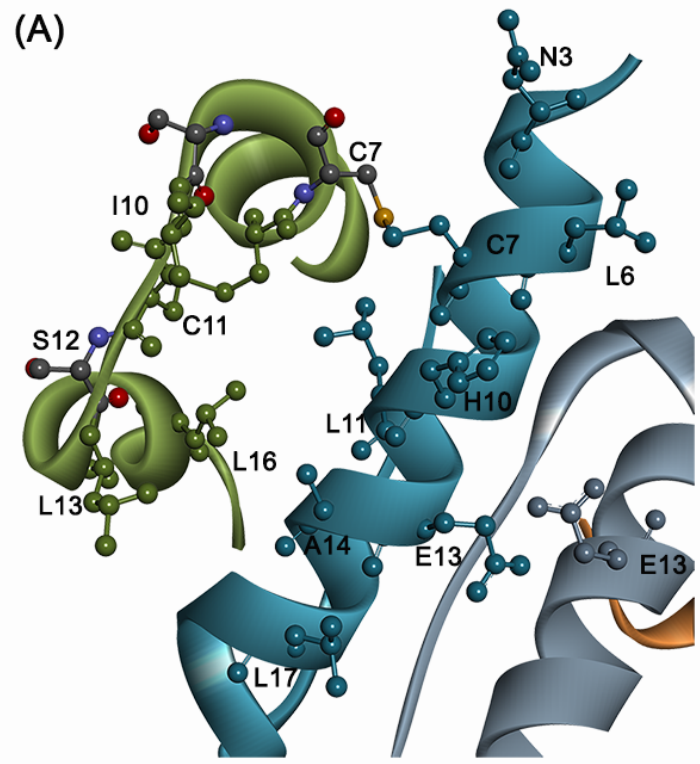

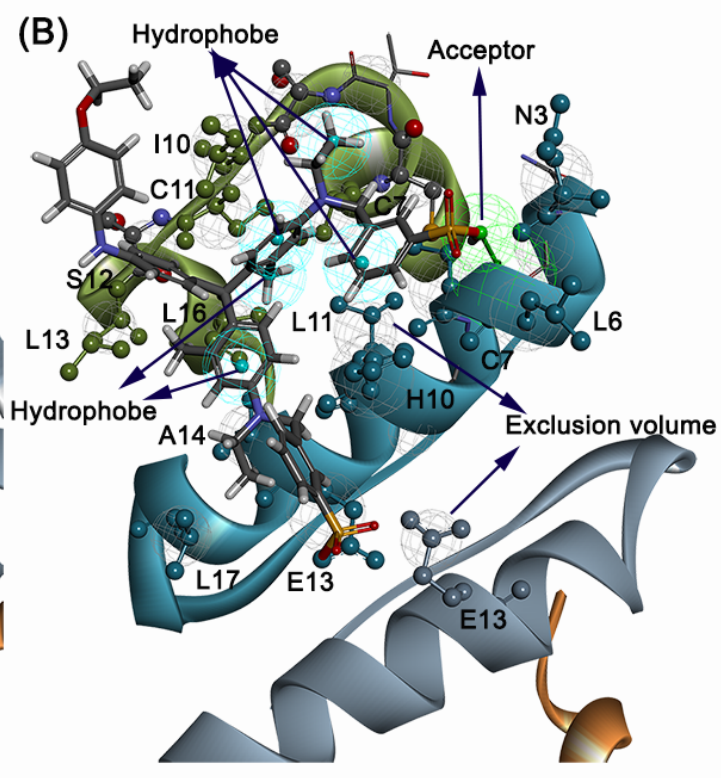

Figure 9. Mapping of important residues involved in CBBG interaction and its pharmacophore model. A) Residues highlighted from NMR and Molecular docking interactions. B) Receptor ligand-based pharmacophore model reveals the five hydrophobic features at the $\mathrm{AB}$ interface and acceptor feature in the vicinity of $\mathrm{C} 7$ and $\mathrm{N} 3$ residues. 


\section{Tables}

Table 1: Binding constants and thermodynamic of binding between CBBG and insulin form ITC and NMR experiment.

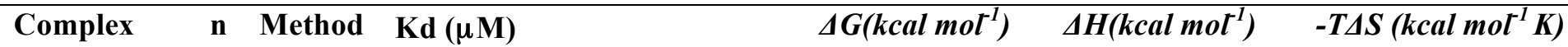

\begin{tabular}{|c|c|c|c|c|c|c|}
\hline Insulin-CBBG & 2 & $\begin{array}{c}\text { ITC } \\
\text { NMR }\end{array}$ & $\begin{array}{l}12.5 \\
7.50 \pm 1.56 \text { (aliphatic region) } \\
5.26 \pm 1.64 \text { (aromatic region) } \\
7.54 \pm 2.56 \text { (amide region) }\end{array}$ & -11.1 & -57.2 & 46.1 \\
\hline
\end{tabular}

Table 2: Lag time and Growth Rate Constants for Insulin amyloid fibrillation formation ( different concentrations and conditions see in Method Material) and in the presence and absence of CBBG).

\begin{tabular}{cccc}
\hline condition & reaction & lag phase & $\begin{array}{c}\text { apparent rate } \\
\left(k_{\text {app }}\right)\end{array}$ \\
\hline Insulin $100 \mu M, p H \sim 1.6$ & $H I$ & $1.8 \mathrm{~h}$ & $0.83 \mathrm{~h}^{-1}$ \\
Insulin $320 \mu M, p H \sim 1.6$ & $H I$ & $1.6 \mathrm{~h}$ & $0.95 \mathrm{~h}^{-1}$ \\
$C B B G 17.5 \mu M$ & $H I / C B B G 1$ & $3.06 \mathrm{~h}$ & $0.42 \mathrm{~h}^{-1}$ \\
$C B B G 215 \mu M$ & $H I / C B B G 2$ & $3.32 \mathrm{~h}$ & $0.42 \mathrm{~h}^{-1}$ \\
$C B B G 330 \mu M$ & $H I / C B B G 3$ & $3.68 \mathrm{~h}$ & $0.32 \mathrm{~h}^{-1}$ \\
Insulin $100 \mu M, p H \sim 7.2$ & $H I$ & $1.6 \mathrm{day}$ & $0.88 \mathrm{day}^{-1}$ \\
\hline
\end{tabular}

\section{TOC}




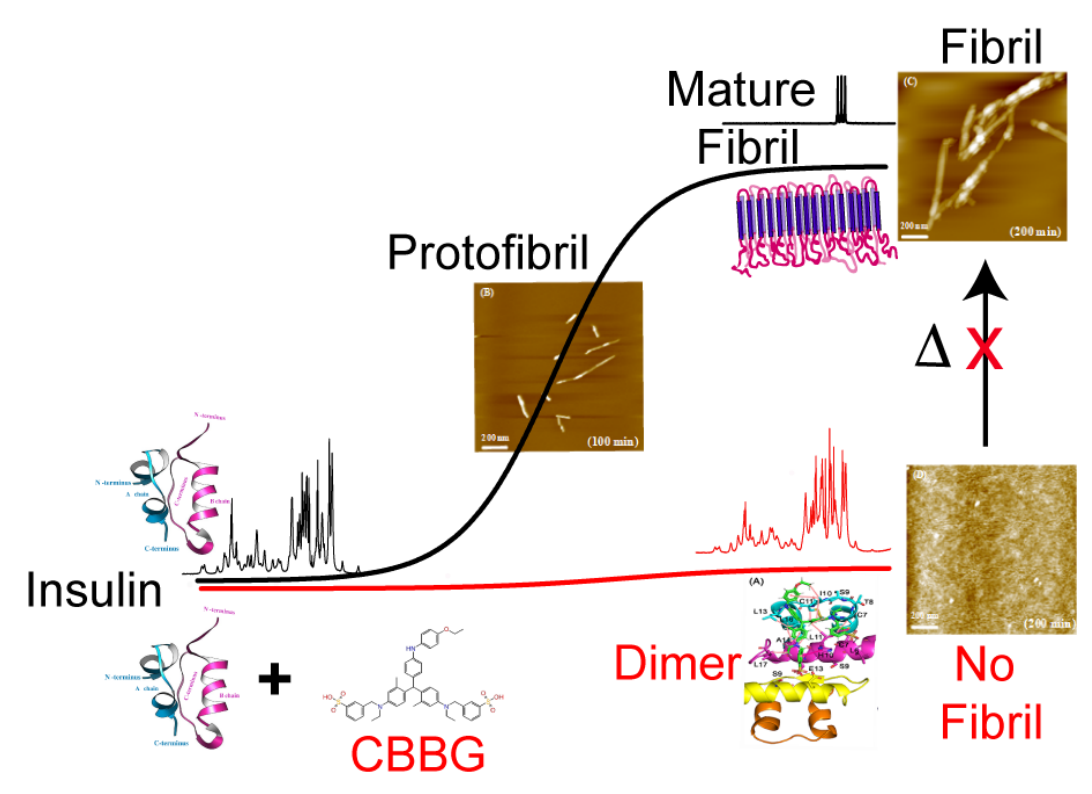

